\title{
Dendritic cell biology and its role in tumor immunotherapy
}

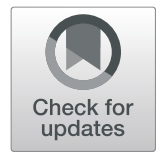

Yingying Wang ${ }^{1,2,3,4+}$ D, Ying Xiang ${ }^{2,3+}$, Victoria W. Xin ${ }^{5 \dagger}$, Xian-Wang Wang ${ }^{2,6}$, Xiao-Chun Peng ${ }^{2,7}$, Xiao-Qin Liu ${ }^{2,3,8}$, Dong Wang ${ }^{2,3}, \mathrm{Na} \mathrm{Li}^{9}$, Jun-Ting Cheng ${ }^{2,3}$, Yan-Ning Lyv ${ }^{10}$, Shu-Zhong Cui ${ }^{1}$, Zhaowu Ma ${ }^{2,3^{*}}$, Qing Zhang ${ }^{11,12^{*}}$ and Hong-Wu Xin ${ }^{2,3,13^{*}}$

\begin{abstract}
As crucial antigen presenting cells, dendritic cells (DCs) play a vital role in tumor immunotherapy. Taking into account the many recent advances in DC biology, we discuss how DCs (1) recognize pathogenic antigens with pattern recognition receptors through specific phagocytosis and through non-specific micropinocytosis, (2) process antigens into small peptides with proper sizes and sequences, and (3) present MHC-peptides to $\mathrm{CD}^{+}$and $\mathrm{CD} 8^{+} \mathrm{T}$ cells to initiate immune responses against invading microbes and aberrant host cells. During anti-tumor immune responses, DC-derived exosomes were discovered to participate in antigen presentation. T cell microvillar dynamics and TCR conformational changes were demonstrated upon DC antigen presentation. Caspase-11-driven hyperactive DCs were recently reported to convert effectors into memory T cells. DCs were also reported to crosstalk with NK cells. Additionally, DCs are the most important sentinel cells for immune surveillance in the tumor microenvironment. Alongside DC biology, we review the latest developments for DCbased tumor immunotherapy in preclinical studies and clinical trials. Personalized DC vaccine-induced T cell immunity, which targets tumor-specific antigens, has been demonstrated to be a promising form of tumor immunotherapy in patients with melanoma. Importantly, allogeneic-lgG-loaded and HLA-restricted neoantigen DC vaccines were discovered to have robust anti-tumor effects in mice. Our comprehensive review of DC biology and its role in tumor immunotherapy aids in the understanding of DCs as the mentors of T cells and as novel tumor immunotherapy cells with immense potential.
\end{abstract}

Keywords: Dendritic cells (DCs), MHC, Immune cells, Tumor immunotherapy

\section{Introduction}

Antigen presenting cells (APCs) play a significant role in both innate and adapted immunity responses. The category of APCs consists of macrophages, dendritic cells (DCs), and B lymphocytes [1]. DCs, first discovered by Ralph Steinman in 1973, are the most important of the

\footnotetext{
*Correspondence: zhaowu823@126.com; Isszq@mail.sysu.edu.cn; hongwu_xin@126.com

†Yingying Wang, Ying Xiang and Victoria W. Xin contributed equally to this work.

2Laboratory of Oncology, Center for Molecular Medicine, School of Basic Medicine, Faculty of Medicine, Yangtze University, 1 Nanhuan Road, Jingzhou 434023, Hubei, China

${ }^{11}$ State Key Laboratory of Biocontrol, School of Life Sciences, Sun Yat-sen University, Guangzhou 510275, China

Full list of author information is available at the end of the article
}

APCs and have many different subtypes. These subtypes have a variety of special functions in immunological processes, such as initiating immune reactions, regulating immune responses, and maintaining those responses [2]. According to its ontogeny, a DC can be categorized as either a conventional DC (cDC) or a plasmacytoid DC (pDC), as summarized in Table 1 [3]. Also, according to the developmental stage of the DC, it can be classified into two major categories: immature and mature [4]. Most immature DCs reside on mucosal surfaces, with the skin and solid organs acting as sentinels to recognize antigens. These DCs have a lower expression of major histocompatibility complex (MHC) I and MHC II, T cell co-stimulation factors, and adhesion molecules [3]. 
Table 1 DC classification

\begin{tabular}{|c|c|c|c|c|c|c|}
\hline \multirow{2}{*}{$\begin{array}{l}\text { DC } \\
\text { subtype }\end{array}$} & \multirow[t]{2}{*}{ Identification basis } & \multirow[t]{2}{*}{ Presence in vivo } & \multicolumn{2}{|l|}{ Main surface markers } & \multirow{2}{*}{$\begin{array}{l}\text { Secreted } \\
\text { molecules }\end{array}$} & \multirow[t]{2}{*}{ Function } \\
\hline & & & Mouse & Human & & \\
\hline $\mathrm{pDCs}$ & $\begin{array}{l}\text { 120G8+, B220+, } \\
\text { CD11c+, LY6C+, } \\
\text { CD11b- }\end{array}$ & $\begin{array}{l}\text { Circulate through the blood } \\
\text { and lymphoid tissues }\end{array}$ & $\begin{array}{l}\text { TLR7, TLR9, TLR12, RLR, } \\
\text { STING, CLEC12A }\end{array}$ & $\begin{array}{l}\text { TLR7, TLR9, RLR, STING, } \\
\text { CLEC12A }\end{array}$ & $\begin{array}{l}\text { CD317, } \\
\text { SIGLECH, } \\
\text { B220, } \\
\text { BDC2*, } \\
\text { BDC4* }\end{array}$ & $\begin{array}{l}\text { (1) Type I } \\
\text { interferons, (2) } \\
\text { antigen } \\
\text { presentation, (3) T } \\
\text { cell priming }\end{array}$ \\
\hline $\mathrm{cDC} 1 \mathrm{~s}$ & $\begin{array}{l}\text { CDC1s } \\
\text { (XCR1hiCD172low) }\end{array}$ & $\begin{array}{l}\text { Thymus, spleen and lymph } \\
\text { nodes }\end{array}$ & $\begin{array}{l}\text { TLR2-, TLR4, TLR11- } \\
\text { TLR13, STING, CLEC12A }\end{array}$ & $\begin{array}{l}\text { TLR1, TLR3, TLR6, TLR8, } \\
\text { TLR10, STING, CLEC12A }\end{array}$ & $\begin{array}{l}\text { XCR1, } \\
\text { CLEC9A, } \\
\text { (CD103), } \\
\text { (CD8a), } \\
\text { BDCA3* }\end{array}$ & Cross-priming \\
\hline $\mathrm{cDC} 2 \mathrm{~s}$ & $\begin{array}{l}\text { CDC2s } \\
\text { (XCR1lowCD172hi) }\end{array}$ & $\begin{array}{l}\text { Thymus, spleen and lymph } \\
\text { nodes }\end{array}$ & $\begin{array}{l}\text { TLR1, TLR2, TLR4-TLR9, } \\
\text { TLR13, RLR, NLR, STING, } \\
\text { CLEC4A, CLEC6A, } \\
\text { CLEC7A, (CLEC12A) }\end{array}$ & $\begin{array}{l}\text { TLR1-TLR9, RLR, NLR, } \\
\text { STING, LEC4A, CLEC6A, } \\
\text { CLEC7A, CLEC10A, } \\
\text { CLEC12A }\end{array}$ & $\begin{array}{l}\text { CD11b, } \\
\text { SIRPa, } \\
\text { (CD4), } \\
\text { (DCIR2) }\end{array}$ & $\begin{array}{l}\text { CD4+ T cell } \\
\text { priming }\end{array}$ \\
\hline MoDCs & $\begin{array}{l}\text { CD11c+, Ly6C+, } \\
\text { CD103 }\end{array}$ & $\begin{array}{l}\text { Differentiate from monocytes } \\
\text { in peripheral tissues on } \\
\text { inflammation. Resident in skin, } \\
\text { lung, and intestine }\end{array}$ & $\begin{array}{l}\text { CD11c+, MHC-II+, } \\
\text { CD11b+, Ly6C+, CD64+, } \\
\text { CD206+, CD209+, } \\
\text { CD14+, CCR2+ }\end{array}$ & $\begin{array}{l}\text { CD11c+, MHC-II+, } \\
\text { CD11b+, Ly6C+, CD64+, } \\
\text { CD206+, CD209+, } \\
\text { CD14+, CCR2+, CD103+ }\end{array}$ & $\begin{array}{l}\text { CD11b, } \\
\text { CCR2, LY6C, } \\
\text { CD115 }\end{array}$ & Inflammation \\
\hline
\end{tabular}

Immature DCs do not secrete proinflammatory cytokines. However, they are capable of migration.

When immature DCs uptake antigens, they shift to secondary lymphoid organs and present antigens to helper $\mathrm{T}$ cells or effector $\mathrm{T}$ cells to trigger specific cytotoxic $\mathrm{T}$ lymphocyte (CTL) responses [5]. In the meantime, they also gradually become more motile and upregulate the expression of $\mathrm{CC}$-chemokine receptors 7 , 8 (CCR7, 8) [6].

On the other hand, matured DCs have a reduced ability to uptake and process antigens but have an enhanced migration capacity. In addition, mature DCs were also reported to have an increased expression of various costimulatory molecules-for instance, CD40, CD70, and CD80, as well as CD86-and an increased production of proinflammatory cytokines and chemokines [7, 8].

Here, we review the latest studies on DCs as the mentors of $\mathrm{T}$ cells, with an emphasis on how DCs specifically recognize, process, and present antigens to program $\mathrm{T}$ cells for immune activation, suppression, or memorization. We also highlight some recent developments that demonstrate the immense potential of DCs in tumor immunotherapy.

\section{Antigen recognition and internalization}

DCs are highly dynamic, using their specific receptors to recognize foreign invading antigens or aberrant selfantigens. DCs recognize antigens through pathogenassociated molecular patterns (PAMPs) as well as danger-associated molecular patterns (DAMPs) through pattern recognition receptors (PRRs). DCs then uptake, process, and present antigens to $\mathrm{T}$ cells to initiate immune responses (Fig. 1a).

\section{Specific phagocytosis}

The critical approach of antigen uptake by DCs and other immune cells is generally believed to be phagocytosis [7]. There are two important forms of phagocytosis: microautophagy and chaperone-mediated autophagy (Fig. 1a). Microautophagy is initiated when the expression of master regulator RAB5A is altered and the MHC-II compartment (MIIC) is fused by the autophagy protein LC3. As a key endocytic protein, the master regulator RAB5A also has multiple physiological activities, such as promoting coherent and ballistic collective motility, impacting junctional mechanics and monolayer rigidity, and increasing endomembrane trafficking [9]. Chaperones, such as C-type lectins and Fc receptors, can recognize antigens by targeting special ligands of apoptotic cells or pathogens. Afterwards, the endocytosis process, mediated by clathrin, is induced, which places antigens into antigen-processing compartments [10]. Here, we have highlighted the major mechanisms of chaperone-mediated autophagy.

\section{C-type lectin receptors (CLRs)}

Pattern-recognition receptors are critical components to immune responses. They recognize invading microbes and induce protective immune responses to infection. CLRs, a type of pattern-recognition receptor, are central to antifungal immunity. They are expressed on macrophages as well as DCs. Dectin-1, CLEC9, and DEC-205 (lymphocyte antigen 75) are all examples of CLRs [10]. Specifically, the calcium-dependent carbohydrate recognition domains (CRD) in CLRs recognize conserved fungal cell-wall carbohydrates and their glycosylation pattern, also known as the carbohydrate fingerprint [11]. 
Table 2 Fc receptor classification and function

\begin{tabular}{|c|c|c|c|c|c|c|c|c|}
\hline \multirow[t]{2}{*}{$\mathrm{FcR}$} & \multirow[t]{2}{*}{ Type } & \multirow{2}{*}{$\begin{array}{l}\text { Affinity } \\
\text { of } \\
\text { binding } \\
\operatorname{lgG}\end{array}$} & \multirow{2}{*}{$\begin{array}{l}\text { Function } \\
\text { domain }\end{array}$} & \multirow{2}{*}{$\begin{array}{l}\text { Fc } \\
\text { signal }\end{array}$} & \multicolumn{2}{|l|}{ Fc expression cells } & \multirow[t]{2}{*}{ Short-term effects } & \multirow[t]{2}{*}{ Long-term effects } \\
\hline & & & & & Constitutive & Inducible & & \\
\hline$\overline{F c R I}$ & 1 & High & $\begin{array}{l}\mathrm{Fc} \\
\text { domains } \\
\text { within IgG }\end{array}$ & ITAM & Monocytes & $\begin{array}{l}\text { Neutrophils, } \\
\text { eosinophils, } \\
\text { dendritic } \\
\text { cells }\end{array}$ & - & - \\
\hline FcrRIlla & । & Low & $\begin{array}{l}\text { Fc } \\
\text { domains } \\
\text { within lgG }\end{array}$ & ITAM & $\begin{array}{l}\text { Monocytes, } \\
\text { neutrophils, } \\
\text { eosinophils, } \\
\text { macrophages, } \\
\text { dendritic cells, } \\
\text { platelets, granulocytes }\end{array}$ & - & $\begin{array}{l}\text { Degranulation, } \mathrm{ROI} \\
\text { production, } \\
\text { phagocytosis, cytokine, } \\
\text { chemokine expression, } \\
\text { platelet activation }\end{array}$ & $\begin{array}{l}\text { Proinflammatory molecule stimulation } \\
\text { and release, cell survival, motility, } \\
\text { platelet binding to leukocytes, } \\
\text { enhanced antigen process, } \\
\text { presentation, T cell responses }\end{array}$ \\
\hline FcrRIllb & । & Low & $\begin{array}{l}\text { Fc } \\
\text { domains } \\
\text { within lgG }\end{array}$ & ITIM & $\begin{array}{l}\text { B cells, monocytes, } \\
\text { neutrophils, } \\
\text { eosinophils, } \\
\text { macrophages, } \\
\text { dendritic cells, plasma } \\
\text { cells }\end{array}$ & - & B cell selection & High-affinity lgG responses \\
\hline FcrRIlla & । & Low & $\begin{array}{l}\mathrm{Fc} \\
\text { domains } \\
\text { within lgG }\end{array}$ & ITAM & NK cells & $\begin{array}{l}\text { Dendritic } \\
\text { cells }\end{array}$ & $\begin{array}{l}\text { Phagocytosis, cytokine } \\
\text { and chemokine } \\
\text { expression, cell } \\
\text { activation, degranulation }\end{array}$ & $\begin{array}{l}\text { Monocyte recruitment, differentiation, } \\
\text { proinflammatory pathway stimulate, } \\
\text { cytotoxicity, cell survival, effector } \\
\text { leukocyte impact, immune complexes } \\
\text { generation }\end{array}$ \\
\hline FcrRIIllb & । & Low & $\begin{array}{l}\text { Fc } \\
\text { domains } \\
\text { within lgG }\end{array}$ & ITAM & Granulocytes & Neutrophils & $\begin{array}{l}\text { Degranulation, } \mathrm{ROI} \\
\text { production, } \\
\text { phagocytosis }\end{array}$ & $\begin{array}{l}\text { Proinflammatory molecule release, } \\
\text { cell survival, motility, myeloid } \\
\text { leukocyte impact }\end{array}$ \\
\hline $\begin{array}{l}\text { DC- } \\
\text { SIGN }\end{array}$ & $\|$ & - & $\begin{array}{l}\text { Sialylated } \\
\text { Fc } \\
\text { glycoforms }\end{array}$ & & & & $\begin{array}{l}\text { Phagocytosis, cytokine } \\
\text { and chemokine } \\
\text { expression }\end{array}$ & $\begin{array}{l}\text { Macrophage polarization, lgG- } \\
\text { mediated inflammation }\end{array}$ \\
\hline DC23 & $\|$ & - & $\begin{array}{l}\text { Sialylated } \\
\text { Fc } \\
\text { glycoforms }\end{array}$ & & B cells & $\begin{array}{l}\text { T cells, } \\
\text { monocytes, } \\
\text { neutrophils, } \\
\text { eosinophils }\end{array}$ & B cell selection & $\begin{array}{l}\text { Constitutive high-affinity lgG } \\
\text { responses }\end{array}$ \\
\hline
\end{tabular}

Note: High-affinity FçR, capable of binding monomeric lgG; low-affinity $F c \gamma R$, variable affinities by subclasses

The melanin-sensing C-type lectin receptor MelLec plays a major role in antifungal immunity by recognizing naphthalene-diol of 1,8-dihydroxynaphthalene (DHN)melanin. MelLec has the ability to identify the conidial spores of Aspergillus fumigatus and other DHNmelanized fungi $[12,13]$. The C-Type lectin 5A (CLEC5A) is a spleen tyrosine kinase (Syk)-coupled receptor of APC and plays a pivotal role in the activation of innate immunity against viruses-especially Flavivirus [14]. CLEC5A promotes neutrophil extracellular trap development and the production of both reactive oxygen species and proinflammatory cytokines by recognizing the bacteria Listeria monocytogenes. It can also induce inflammasome activation in macrophages and stimulate the immune reaction of $\mathrm{T}$ cells [14].

The human DC-specific intercellular adhesion molecule-1 grabbing nonintegrin (DC-SIGN or CD209) is thought to be a canonical of the C-type lectin receptor expressed on both macrophages and DCs [15]. It is a type 2, mannose-specific C-type lectin that also works as a cytosolic DNA-sensor. It induces specific immune responses upon the recognition of glycans through its carbohydrate recognition domains (CRD) [16, 17]. After DC-SIGN recognizes fucose-based PAMPs, it activates IKKe. In turn, IL-27 is produced, follicular T helper cell (TFH) differentiation is facilitated, B cell IgG production is stimulated, B cell survival is aided, and Th2 differentiation is implemented [18, 19]. DC-SIGN can be bound by adaptor protein LSP1 in combination with a triad "signalosome" complex consisting of the adaptor proteins KSR1, CNK, and kinase [19]. The binding of pathogens to these lectins results in an internalization to endosomal compartments, where the pathogens are destroyed and an immune response is initiated [16]. In addition, Chao et al. found that Annexin A2 (ANXA2), which is abundantly expressed in nasopharyngeal carcinoma (NPC), can activate DC-SIGN and inhibit DC-mediated immunity against NPC [20]. Both DC maturation and the production of proinflammatory interleukin (IL)-12 were inhibited, but the production of immunosuppressive IL-10 was increased [20]. 


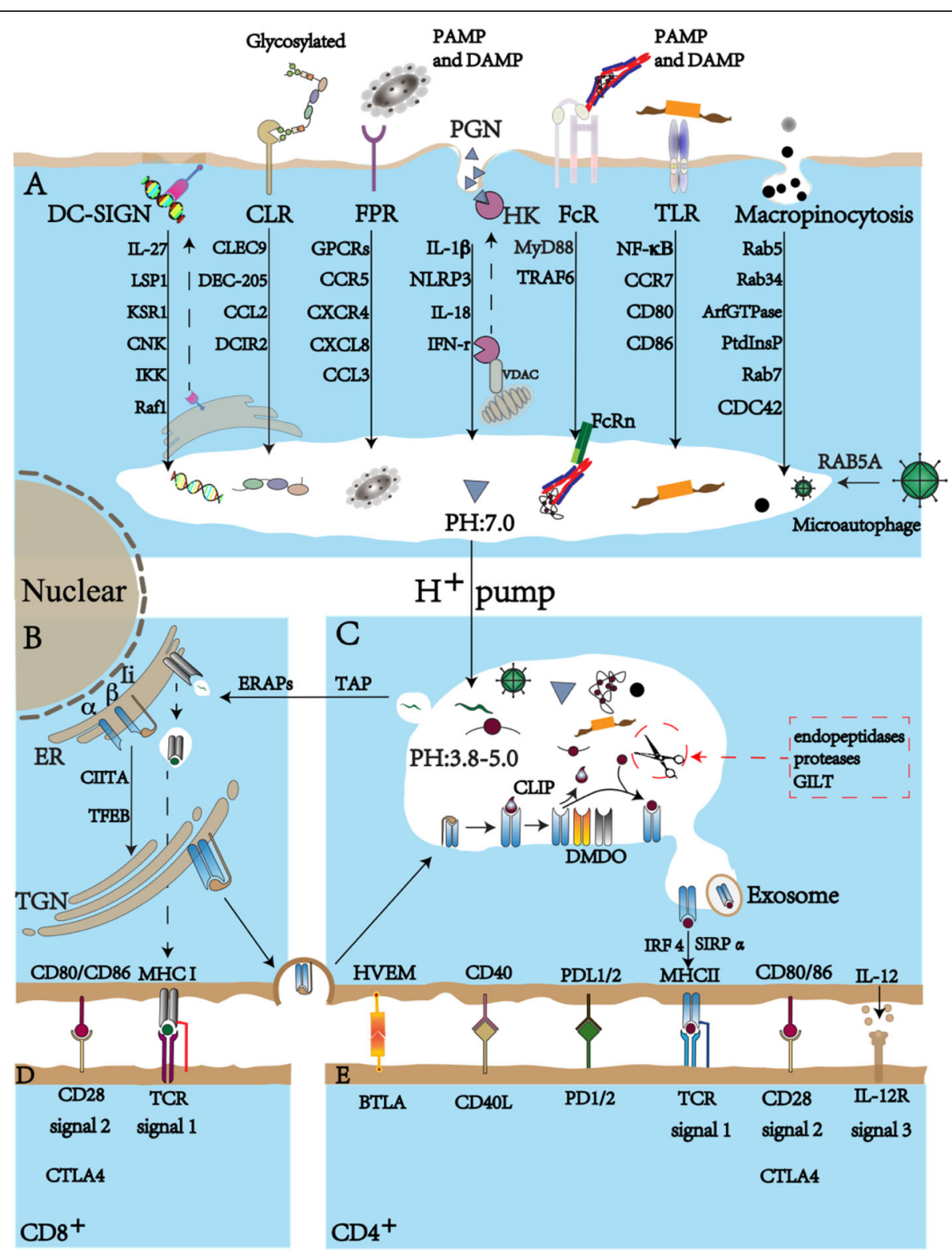

Fig. 1 Pathways of antigen recognition, processing, and presentation of DCs. a Antigen recognition and internalization into the early endosome through specific phagocytosis (microautophagy and chaperone-mediated autophagy) or non-specific macropinocytosis. b Dimers of MHC-I and MHC-II are formed in the endoplasmic reticulum (ER). MHC-II binds with a non-polymorphic invariant chain li (CD 74). c Gradual acidification to approximate $\mathrm{pH} 3.8-5.0$ by the ATP-dependent vacuolar proton pump, increasing the lysosomal enzyme activity in the late endosomal and lysosomal-processing compartments. After proteolytic cleavage, antigens are transferred to MHC molecules. $\mathbf{d}$ MHC-I antigen cross-presentation involved in modulating receptor-mediated signaling. e MHC-II antigen presentation involved in modulating receptor-mediated signaling

\section{Formyl peptide receptors (FPRs)}

FPRs are G protein-coupled receptors (GPCRs) expressed in bone marrow cells and especially on DCs [21]. GPCRs belong to the group of pattern-recognition receptors that can recognize peptides containing $\mathrm{N}$ formylated methionine [21]. There are three human FPRs: FPR1, FPR2, and FPR3. The mice equivalents are unclear [22]. FPRs can induce DC migration to necrotic tumor cells and affect tumor angiogenesis [23]. They can also downregulate the cell surface expression of GPCRs, CCR5, CXCR4, chemokines CXCL8 (also referenced as interleukin 8, IL-8), and CCL3, which in turn promotes monocyte migration, which is involved in tumor growth $[24,25]$. FPRs have five antigen-binding pockets where consecutive amino acid residues can be modified without changing their affinity towards the agonists [26]. FPRs can also induce cell adhesion with the robust release of migrating superoxide granules by recognizing 
transducing chemotactic signals in phagocytes [26]. Yousif et al. reported that the recognition of the UPAR (8495) sequence and the shorter synthetic peptide (Ser88Arg-Ser-Arg-Tyr92, SRSRY) was a fresh, powerful, and steady repressor against FPR1-triggered monocyte trafficking and cell migration [26].

\section{NOD-like receptor NLRP3 and Hexokinases}

The glycolytic enzyme hexokinase is an innate immune receptor which monitors bacterial peptidoglycan (PGN) by recognizing $\mathrm{PGN}$-produced $\mathrm{N}$-acetylglucosamine (NAG) in the cytosol [27]. The degradation of Grampositive bacterial cell walls by the phagosomes of DCs will lead to the activation of the NOD-like receptor family, pyrin domain-containing 3 (NLRP3), which promotes the release of hexokinase [27]. Moreover, when NAG binds with hexokinase, it induces the secretion of proinflammatory interleukins IL- $1 \beta$ and IL-18 $[27,28]$. Uncontrolled IL-1 $\beta$ release can lead to autoinflammatory diseases such as Cryopyrin-associated periodic syndrome (CAPS) or Mediterranean fever. The overproduction of IL-18 can also cause autoinflammatory diseases such as rheumatoid arthritis. IL-18 functions to promote inflammation primarily through stimulating the production of IFN- $\gamma$, which is a classic anti-microbial inflammatory cytokine [29].

\section{Fc receptors}

Expressed on hematopoietic cells, Fc receptors (FcRs) play an important role in immune responses by binding to the Fc region of an antibody. FcRs can bind to different immunoglobulins (IgA, IgM, IgE, and IgG), participating in antibody-mediated innate and adaptive immune responses (Table 2) [30]. A review by van de Winkel has introduced the classification of Fc receptors in detail [31]. In humans, activated Fc receptors include FcRI (CD64), FcRIIA (CD32a), FcRIIC (CD32c), FcRIIIA (CD16a), and FcRIIIB (CD16b) [32]. Most members of the Fc receptor family generally bind to extracellular IgGs, excluding the neonatal Fc receptor (FcRn) and the intracellular Fc acceptor tripartite motif-containing protein 21 (TRIM21). FcRI has the highest affinity for monomeric IgG1, the lowest affinity for monomeric IgG2, and a medium level of affinity for IgG3 and IgG4. Mostly, FcRI is saturated and in a steady condition in the presence of physiological serum. The binding complexes (FcR-IgG) not only trigger activating signals, but also mediate inhibitory signals [33]. The complexes affect the intensity of the immune reactions by settingup a "threshold" via a tyrosine-based activation motif (ITAM) or immune receptor tyrosine-based inhibitory motif (ITIM) in their cytoplasmic tails. ITIM phosphorylation has an immunosuppressive effect by inducing the recruitment of phosphatases, including SHIP-1 and inositol polyphosphate-5-phosphatase (INPP5D). Recent studies suggest that only monocyte-derived DCs and macrophages express high levels of activated Fc receptors for IgG [34]. FcRn works as an intracellular IgG Fc binding receptor and is encoded by the Fcgrt gene. FcRn is a lifelong resident of the endolysosomal system in most hematopoietic cells, including DCs, and can guide antibody-bound viruses and other antigens to the proteasome by activating E3 ubiquitin ligase [33]. After the FcRs-IgG-peptide complex internalization is completed via FcRn, FcRn releases IgG-peptides into the acidifying endosomes, where the peptides can be successfully processed into peptide epitopes to be loaded onto MHC-I or MHC-II molecules to activate $\mathrm{CD}^{+}$or $\mathrm{CD}^{+}{ }^{+} \mathrm{T}$ cells $[35,36]$.

FcRn in DCs can also lead directly to the activation of $\mathrm{CD}^{+} \mathrm{T}$ cells [37]. An experiment showed that DCs isolated from wild type mice pre-incubated with IgGpeptides were able to effectively prime $\mathrm{CD} 4^{+} \mathrm{T}$ cells [37]. In contrast, DCs isolated from $\mathrm{Fcgrt}^{-/-}$mice needed antigen concentrations nearly 1000 times higher than that for normal mice, suggesting that FcRn significantly strengthens the ability of DCs to generate MHCII compatible epitopes from antigens delivered by IgGpeptides [38].

\section{Toll-like receptors (TLRs)}

Discovered in 1996, TLRs are type I transmembrane proteins [39]. TLRs reside on the surfaces of immune cells or intracellular compartments and recognize PAMPs for immune responses against pathogens and neoplastic cells. TLRs induce DC maturation by activating nuclear factor kappa $\mathrm{B}(\mathrm{NF}-\kappa \mathrm{B})$ and upregulating the expression of CCR7, MHC-II, and co-stimulatory CD80 or CD86 [40, 41]. At least two members of the Toll-like receptor (TLR) family-TLR7 and TLR9-can recognize self-RNA/DNA, respectively [42]. A new report found that the TLR trafficking chaperone UNC93B1 specifically limited the signaling of TLR7, but not TLR9, and prevented TLR7-dependent autoimmunity in mice [42]. Comprehensive analyses reveal that both TLR2 and TLR4 are required to recognize Sel1, activate NF-kB and MAPK signaling pathways, and lead to the expression of proinflammatory cytokines and chemokines against Candida albicans infections [43].

TLRs are also expressed on tumor cells for the purpose of immune evasion [44]. The stimulation of TLR3 and TLR5 signaling can induce an anti-tumor $\mathrm{T}$ cell response. However, TLR4, TLR7, TLR8, and TLR9 mediated chronic inflammations were found to have pro-tumor effects. On the other hand, a novel PAMP-mimicking regent can activate macrophage-mediated tumor immunotherapy.

A specific agonist of TLR2 modified by acetyl groups with a substitution degree of 1.8 (acGM-1.8) was found 
to stimulate macrophages to release anti-tumor proinflammatory cytokines. Another small-molecule agonist of TLR7, 2-methoxyethoxy-8-oxo-9-(4-carboxybenzyl) adenine (1V209), was found to enhance adjuvant activity and limit adverse events when conjugated to hollow silica nanoshell s[45].

\section{Non-specific macropinocytosis}

Macropinocytosis is a type of non-specific phagocytosis in the form of cell "drinking". It can be spontaneously induced by the engagement of growth factors, chemokines, or Toll-like receptors (TLRs) $[11,46]$. TLRs are dependent on extracellular $\mathrm{Ca}^{+}$-sensing receptors (CaSR) [47]. Regulatory factors like Rab5, Rab34, and ArfGTPases contribute to early macropinosome maturation [12]. Rab5 and PtdIns (3)P then synergize to promote fusion with early endosomes with the involvement of EEA1 [10]. The homotypic fusion and protein sorting (HOPS) complex, septins, and SNARE proteins endow the late compartment vacuoles with vacuolar-type $\mathrm{H}^{+}$ATPase (V-ATPase) at low $\mathrm{pH}$ values so that degradative enzymes can function optimally [13]. At this moment, a critical switch from Rab5 into Rab7 promotes the centripetal transportation of the vacuole and its fusion with late endosomal/lysosomal compartments.

\section{MHC expression, assembly, and trafficking in DCs}

MHC molecules have two categories: MHC class I (MHC-I) and MHC class II (MHC-II) [48]. They both exhibit tremendous allelic polymorphism in the peptidebinding groove. This allows them to bind with a diverse range of peptides (Fig. 1b).

\section{MHC expression}

MHC class I molecules are heterodimers that consist of two polypeptide chains: $\alpha$ and $\beta 2$-microglobulin (B2M). The two chains are linked noncovalently via the interaction of B2M and the $\alpha 3$ domain. Only the $\alpha$ chain is polymorphic and encoded by a HLA gene [49]. Dimers of MHC-II are formed in the endoplasmic reticulum (ER), then bind with a non-polymorphic invariant chain Ii (CD 74) (Fig. 1b) [50, 51]. Li, also called a pseudo peptide, has a transport function and low affinity for the peptide-binding groove of MHC-II, which can prevent MHCII from binding to premature antigens [52]. MHC II contains targeting motifs that can direct the Ii-MHCII complex to traffic from the trans-Golgi network (TGN) to the endosomal-lysosomal antigen-processing compartment (MHC-II compartment, MIIC) via clathrin-mediated endocytosis [50]. In the antigenprocessing compartment, $\mathrm{Li}$ is trimmed gradually by a series of proteases, including cathepsin S, and ultimately SPPL2A, to generate the Ii-associated invariant chain peptide (CLIP). This protects the MHC-II groove before the peptide is bound with MHC-II and removed from the CLIP-MHC-II complex via the enzyme DM (HLADM in humans or H2-DM in mice) [53]. DM has a similar structure with MHC-II. It catalyzes peptide acquisition and the dissociation of CLIP in the MIIC through multivesicular bodies (MVB). DM stabilizes MHC-II during peptide interchange and selects for higher binding affinities from the peptide repertoire [50]. After losing CLIP, MHC-II molecules face two possible fates: productively binding with a local peptide and presenting the complex on the cell surface or aggregating and deconstructing the vacant dimers [54]. Although peptide-MHC-II complexes can be generated throughout the endocytic pathway, antigen-processing typically occurs in late endosomal compartments or in lysosomes. These vesicular compartments are enriched with proteolytic enzymes and disulfide reductases. The compartments have sufficiently low $\mathrm{pH}$ values to activate these enzymes (Fig. 1c) [34]. Interferon- $\gamma$ (IFN- $\gamma$ ) induces the expression of the MHC class II transactivator (CIITA), which then converts MHC class II-negative monocytes into MHC class II-presenting functional APCs [55].

\section{MHC assembly}

The receptors on DCs mediate the internalization of antigens into early endosomes, where the $\mathrm{pH}$ value is nearly neutral and the activity of antigen-processing enzymes is low [56]. After internalization, the lysosomal enzyme will activate due to the gradual acidification by the ATP-dependent vacuolar proton pump [57]. At first, the longer peptide precursors will bind to MHC-II. The precursors are then trimmed into shorter peptides [50]. The antigen-processing proteases consist of the serine proteases cathepsin A and G (Cat A, G), the aspartic proteases cathepsin $\mathrm{D}$ and $\mathrm{E}$ (Pepsin family $\mathrm{A} 1 \mathrm{~A}$ ), and the 11 cysteine proteases cathepsins $\mathrm{B}, \mathrm{C}, \mathrm{F}, \mathrm{H}, \mathrm{K}, \mathrm{L}, \mathrm{O}$, S, V, X, and W (Papain family C1A) [58]. Cathepsin S, $\mathrm{B}, \mathrm{H}$, and $\mathrm{Li}$ are also essential for the degradation of $\mathrm{Li}$ from MHC-II [57]. TFEB (transcription factor EB) can also promote lysosome and phagosome acidification and induce protein degradation in DCs [59]. The $\mathrm{pH}$ values of the late endosomal and lysosomal-processing compartments reach approximately 3.8-5.0, allowing the endopeptidases (EXPD) to recognize the most susceptible site for subsequent cleavage on the antigens. Then, GILT/IFI30 reduces certain disulfide bonds of the antigens' secondary structure [54].

\section{MHC-peptide trafficking in DCs}

After proteolytic cleavage, antigens are transferred to nearby MHC-II molecules. In this course, many different "pro-determinants" of antigens are exposed to the acidic vesicular endosomal system [53]. Large prodeterminants may contain more than one MHC-II 
binding region, but the most suitable, most dominant pro-determinant has the strongest binding affinity for MHC-II. This process is known as competitive capture. Once the pro-determinants are bound, their core residues will be protected by the MHC-II inside the lysosomal compartment. Many antigens contain only one dominant determinant in a haplotype [48]. The ER aminopeptidase has recently been identified to take part in antigen-processing guided by MHC. Recent data showed that a peptide of 51 amino acids did not need to be processed, but it was preferable in the competitive capture process than a peptide of half its size. Compared with the 10-mer cytochrome c peptide, the 23-mer peptide had a 32 times higher binding affinity to MHC-II [60].

Endogenous peptides are generated by proteasomal processing, then imported into the ER where the majority of MHC-I are loaded via the action of the transporter associated with antigen-processing (TAP) (Fig. 1c) [61, 62]. The closed-end of MHC-I molecules only binds to short peptides containing 8-10 amino acids [63]. Before being loaded to MHC-I molecules, the peptide must be trimmed by ER aminopeptidase (ERAP) chaperones, such as calnexin and calreticulin [53]. The specificity of the proteasome, including ERAAP/ERAP1, trypsin, and TAP, can influence epitope generation and transportation to receptive MHC-I molecules [62]. The MHC-Ipeptide complex is generally presented to CD8 T cells, which induce the phosphorylation of the ITAM motifs in TCR through a proto-oncogene tyrosine-protein kinase and the Src (SRC) family kinases pathway [54].

Exogenous antigens are usually presented by MHC-II molecules. Before binding to peptides, MHC-II molecules must release CLIP and then generate an open groove for binding [64]. The open groove of MHC-II, containing a 9-amino acid glove cast (3-4 MHC-II anchor residues), tends to bind to longer peptide fragments (>11 amino acids) [53]. Peptide-MHC-II complexes in DCs leave the antigen-processing compartments and traffic for the plasma membrane, where they can interact with $\mathrm{T}$ cells. Microvilli on T cell surfaces act as detectors for these complexes and can continue moving to detect p-MHC. Different peptides are exchanged until the peptide with the highest affinity binds the TCR grooves [65]. Dynamic interactions between APCs and T cells require several hours to several days [66]. The MHC-II peptidome contains high-affinity and low-affinity peptides. IRF4 regulatory $\mathrm{CD}_{11 \mathrm{~b}^{+}} \mathrm{DC}$ subsets enhance peptideMHC-II complex formation and present antigens to helper $\mathrm{T}$ cells in order to stimulate them [52].

\section{Antigen presentation}

To activate $\mathrm{CD}^{+}$or $\mathrm{CD}^{+}{ }^{+} \mathrm{T}$ cells, several signals are needed (Fig. 1d, e): Signal 1: Antigenic peptides bound to MHC-I or MHC-II molecules are presented to CD8 ${ }^{+}$ $\mathrm{T}$ cells or $\mathrm{CD} 4^{+} \mathrm{T}$ cells, respectively [67]. Signal 2: Appropriate co-stimulatory signaling is delivered through the balance between diverse positive and negative signal $\mathrm{s}[60]$. CD80/CD86 and programmed death-ligand 1 or 2 (PDL1/2) are examples of the positive and negative signals on DC surfaces [68]. Signal 3: T cell stimulatory cytokines are produced by DCs. Examples of such cytokines are proinflammatory interferons (IFNs) and interleukin-12 (IL-12) [69]. These cytokines also stimulate the functional expansion and memory development of CTLs.

\section{Classic antigen presentation to $\mathrm{T}$ cells}

The $\mathrm{T}$ cell receptor (TCR) or TCR-CD3 complex consists of four subunits-an antigen-binding TCR $\alpha \beta$ (or $\mathrm{TCR} \gamma \delta)$ subunit and three signaling subunits $(\mathrm{CD} 3 \varepsilon \delta$, $\mathrm{CD} 3 \varepsilon \gamma$, and $\mathrm{CD} 3(\zeta)$ - and initiates antigen-specific immune responses [70]. As they do not contain cytoplasmic signaling motifs, the TCR $\alpha \beta$ and TCR $\gamma \delta$ subunits cannot trigger intracellular activation signaling pathways upon recognizing antigens on APCs. TCR-mediated signals are transmitted across the cell membrane by CD3 chains, including $\mathrm{CD} 3 \gamma, \mathrm{CD} 3 \delta, \mathrm{CD} 3 \varepsilon$, and $\mathrm{CD} 3 \zeta$. All CD3 chains contain ITAMs in their cytoplasmic domain. $\mathrm{CD} 3 \varepsilon, \mathrm{CD} 3 \gamma$, and $\mathrm{CD} 3 \delta$ each contain one ITAM in their cytoplasmic domain, whereas $\mathrm{CD} 3 \zeta$ contains three ITAMs [71]. The antigen presentation process by peptide-MHC to TCRs can be divided into two stages: the transformation of TCR structure from "closed to open" and the phosphorylation activation of the ITAMs of TCR [66]. TCR interaction with distinct peptideMHC can trigger distinct conformational changes. MHC-I-peptide and MHC-II-peptide complexes on the surface of DCs are presented to TCR complexes on $\mathrm{CD}^{+}$and $\mathrm{CD} 4^{+} \mathrm{T}$ cells, respectively, which in turn promote $\mathrm{T}$ cell activation, proliferation, and differentiation (Fig. 1e, f) [72].

\section{Cross-presentation and cross-priming}

Cross-presentation is the process wherein DCs take up, process, and present extracellular antigens via MHC-I molecules to $\mathrm{CD}^{+} \mathrm{T}$ cells. This is also known as crosspriming [73]. Cross-presentation is necessary to activate $\mathrm{CD}^{+} \mathrm{T}$ cells and has a considerable effect on immune surveillance in transplants and immune defense in infections. Only DCs can cross-prime for a cytotoxic $\mathrm{CD}^{+} \mathrm{T}$ cell response [62]. Particularly, XCR1 ${ }^{+}$DCs are crucial for cross-presentation and communication between $\mathrm{CD}^{+}$and $\mathrm{CD}^{+} \mathrm{T}$ cells in a productive vaccinia virus (VV) infection [74]. Many factors will infect crosspresentation. TLRs can also trigger phagosomal MHC-I transport from the endosomal recycling compartment to facilitate cross-presentation [11]. The absence of FcRn 
will also impair the cross-presentation of IgG-bound internalized antigens by $\mathrm{CD} 8^{-} \mathrm{CD} 11 \mathrm{~b}^{+} \mathrm{DCs}$. TFEB can inhibit the DC presentation of exogenous antigens via MHC-I and promote presentation via MHC-II [75].

\section{Antigen presentation by $D C$ exosomes}

DC-derived exosomes (Dex) are nanometer-sized membrane vesicles that can migrate to tumors or the spleen and present antigens directly or indirectly to CD4+ and CD8+ T cells, thereby inducing immune responses [76]. Several mechanisms have been proposed on how Dex presents antigens via MHC molecules in order to stimulate $\mathrm{T}$ cell responses (Fig. 2).

First, Dex can present antigens to $\mathrm{T}$ cells directly, which is thought to be a restimulation of activated $\mathrm{T}$ cells [77].

Secondly, a process known as cross-dressing occurs. Simply put, it is Dex-mediated indirect antigen presentation to T cells. After binding to APCs, Dex merges with the acceptor APC surface membrane and transfers its peptide/MHC complexes. Following internalization, the Dex peptide/MHC complexes can be reprocessed via endosomal pathways within the APC. Peptide complexes can then be transported back to the DC's surface for presentation to $\mathrm{T}$ cells.

Thirdly, Dex can be internalized by tumor cells and convert tumor cells into stronger immunologic targets for effector immune cells [77]. The mature Dex can activate immature $\mathrm{DCs}$ and $\mathrm{T}$ cells in vitro [78]. Rao et al. reported that DCs pulsed with exosomes from the human hepatocellular carcinoma HepG2 cell line could elicit a stronger antigen-specific CTL response than cell lysates did in vitro and in vivo [79]. DCs can also secrete extracellular vesicles (EVs) of different sizes [76]. Large EVs (IEVs) secreted by immature DCs induce Th2 cytokine secretion (IL-4); small EVs (sEVs) induce Th1 cytokine secretion. Upon DC maturation, all EVs induce Th1 cytokine secretion $[76,80]$.

\section{Immune responses meditated by DCs}

DCs enable $C D 4^{+} T$ cells to activate $B$ and $C D 8^{+} T$ cells

According to their patterns of cytokine production, transcription factor expression, and cell surface marker expression, $\mathrm{CD}^{+} \mathrm{T}$ helper cells are currently subdivided into multiple lineages, encompassing at least Th1, Th2, Th17, and follicular T helper (Tfh) (Fig. 2). CD40, a costimulatory molecule glycoprotein with 277 amino acids also known as TNFRSF5, was originally identified as a receptor on B cells and was later found to be expressed in various other immune effector cells. $\mathrm{T}$ follicular helper cells, a subgroup of $\mathrm{T}$ cells, mediate important cell-cell interactions with B cells that occur within the follicles of secondary lymphoid organs. These $\mathrm{T}$ cells also stimulate and govern $\mathrm{B}$ cells to produce antibodies. The interaction

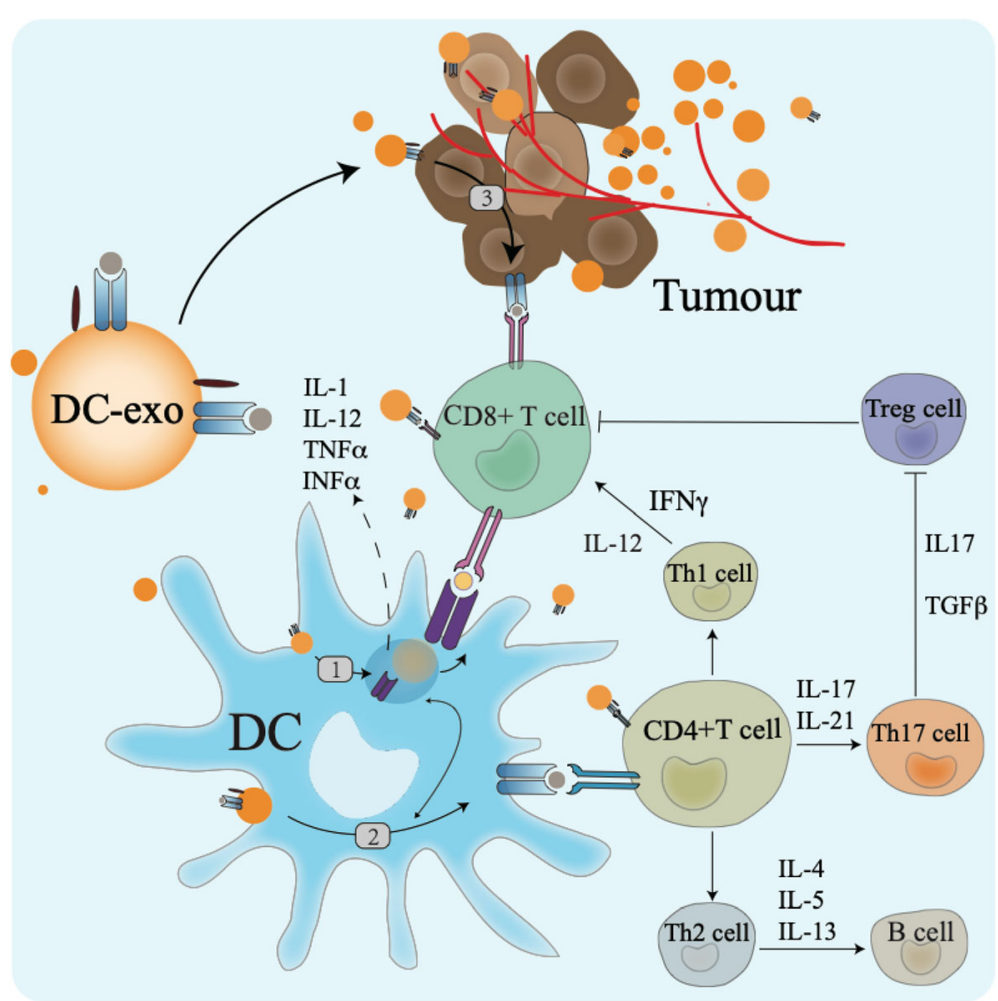

Fig. 2 DC exosome-mediated antigen presentation and T cell activation 
of CD40 on DCs in addition to CD40L on T cells leads to $\mathrm{DC}$ activation, enabling DCs to prime $\mathrm{T}$ cells and induce the upregulation of co-stimulatory molecules, adhesion molecules, and the Th1-polarizing cytokine IL-12 in both mouse and human DCs [81]. Notably, the IL-12 produced after the interaction of CD40 with CD40L plays a decisive role in determining the type of $\mathrm{CD} 4^{+} \mathrm{T}$ cell immunity [69]. IL-12 polarizes the differentiation of naive $\mathrm{CD} 4^{+} \mathrm{T}$ cells into Th1 cells [82]. Th1 and Th2 cells, in turn, secrete interleukin IL-2, IFN $\gamma$, IL-4, IL-5, and IL-13, respectively, to promote $\mathrm{CD}^{+} \mathrm{T}$ and $\mathrm{B}$ cell responses [64]. Th1 cells express the defining T-box transcription factor TBX21 (T-bet), express chemokine receptors such as CXC-chemokine receptor 3 (CXCR3) and CC-chemokine receptor 5 (CCR5), and secrete IFN $\gamma$. Moreover, many $\mathrm{CD}^{+} \mathrm{T}$ cells in the atherosclerotic plaque express other Th1-associated proinflammatory cytokines in addition to IFNy, such as IL-2, IL-3, tumor necrosis factor (TNF), and lymphotoxin, which can all activate macrophages, $\mathrm{T}$ cells, and other plaque cells, accelerating the inflammatory response [83]. The main Th2 cell cytokine is IL-4. IL-4 binds to the IL-4 receptor on $\mathrm{T}$ cells and activates signal transducer and activator of transcription 6 (STAT6), leading to the expression of the transcription factor GATA3, the master regulator of Th2 cell differentiation. In mouse atherosclerotic plaques, a substantial proportion of $\mathrm{T}$ cells express transcripts for Th2 cell-associated cytokines, such as IL-4, IL-5, IL-10, and IL-13 [84].

Recent studies have revealed that primary tumors can induce B cell accumulation into draining lymph nodes (DLN), possibly through signaling mediated by the phosphorylated proteins EGFR, VAV2, P130, CHK2, and CLDN3 in DLN [85-88]. When B cells accumulated in the DLN, they increased the expression of cell cycle related genes Cdc25c, Bub1, Ttk, and Cdk1, and migration-related genes Vcam1, Arhgap5, Cxcr3, and Ccr2. They also secreted chemotactic molecules. In the meantime, these B cells selectively promoted cancer cell lymph node metastasis by producing pathogenic IgG that targeted the glycosylated membrane protein HSPA4 of cancer cells. HSPA4 targeting IgG activated the HSPA4-binding protein ITGB5 and the downstream Src/NF-kB pathway in cancer cells to promote CXCR4/ SDF1 $\alpha$-axis-mediated cancer metastasis $[85,87,88]$.

\section{DCs mediate immune memory}

Immune memory is a vital mechanism of myeloid cell plasticity. It occurs in response to environmental stimuli and alters subsequent immune responses [89]. Two types of immunological imprinting can be distinguished: training and tolerance. These imprinting processes are epigenetically mediated and enhance or suppress subsequent inflammation, respectively [89]. DCs can also mediate immune memory via group 2 innate lymphoid cells (ILC2)
[90]. Memory Th2 cells are essential for the recall response and subsequent type-2-cytokine-driven inflammation [90, 91]. Halim et al. reported that ILC2 is critical in memory Th2 cell immune response [90]. Activated ILC2 can secrete IL-13 to stimulate IRF $4^{+} \mathrm{CD} 11 \mathrm{~b}^{+} \mathrm{CD} 103^{-} \mathrm{DCs}$, generating CCL17 and recruiting $\mathrm{CCR}^{+}$memory Th2 cells [90]. To generate a long-term vaccinal anti-tumor response, many researchers are investigating the conversion of effector $\mathrm{T}$ cells into memory $\mathrm{T}$ cells. The desired antitumor antibodies should be optimized against cytotoxic effects and should be involved in motivating a long-lasting anti-tumor cellular immune response [92]. DiLillo et al. demonstrated that both hFcyRIIIA expressed on macrophages and hFcyRIIA expressed on human DCs (Table 1) generated a potent long-term vaccinal anti-tumor $\mathrm{T}$ cell response upon ADCC-mediated tumor clearance in a FcyR-humanized murine lymphoma model. Zhang et al. reported that $C D 45^{+} \mathrm{RALDH}^{+}$DCs controlled volume expansion and maintenance in the secondary lymphoid organs of germ-free mice [93]. Many factors enhance DC active stages. For example, Zanoni et al. found that microbial products and self-encoded oxidized phospholipids (ox-PAPC) can make DCs hyperactive via a caspase-11 enzyme that bound to ox-PAPC and a bacterial lipopolysaccharide (LPS). Hyperactive DCs are longevous and can convert effector T cells into memory T cells [94].

\section{DCs' effects on Tc1 and Treg cells}

The cardinal features of natural or therapy-induced immuno-surveillance are $\mathrm{CD} 8^{+}$cytotoxic $\mathrm{T}$ lymphocytes (Tc1 cells), which can specifically recognize antigens and produce a particular interferon- $\gamma$ (IFN- $\gamma$ )-centered cytokine pattern [95, 96]. For major human malignancies, the abundance of Tc1 cells in tumors has a positive prognostic impact. It is activated by IL-12 and CCR7mediated $\mathrm{CD}_{103}{ }^{+} / \mathrm{CD} 141^{+}$DCs [95]. CCR7 loss in DCs leads to deficient lymph node $\mathrm{T}$ cell activation and will increase tumor outgrowth [96]. CCR7 expression levels in human tumors correlated positively with signatures of CD $141^{+}$DCs and intra-tumor T cells, as well as better clinical outcomes [96].

DCs present peptide-MHC to TCR and generate IL-2 to promote the development of antigen-specific Treg cells for immune suppression. High levels of type I IFNs will feedback suppress Treg cell expansion [97, 98]. When type I IFNs wane, Treg cells increase the expression of IL-10 to suppress the maturation state of DCs and limit their production of proinflammatory cytokines [99]. Low levels of proinflammatory signals allow for the continued maturation of effector $\mathrm{CD} 8^{+} \mathrm{T}$ cells into functional memory $\mathrm{CD}^{+} \mathrm{T}$ cells [100]. Indoleamine 2, 3dioxygenases (IDO1) expressed in DCs can deplete tryptophan and increase kynurenine, which in turn activates 
Treg cells and exerts important immunosuppressive functions [101].

\section{DC and NK cells crosstalk}

The reciprocally activating crosstalk between DCs and NK cells plays a pivotal role in the innate immune response against cancer and infections [102]. DCs recruit NK cells to the draining lymph nodes and interact with them in a CXCR3-dependent fashion. DCs and NK cells interact through a "touch and go" mode lasting from $300 \mathrm{~s}$ to $4 \mathrm{~h}$ [103]. The interaction induces DCs to produce cytokines IL-12, IL-18, IL-27, type I IFNs, IL-15, and prostaglandin E2 (PGE2), leading to the proliferation of NK cells, the expression of the activation marker CD69, and the release of the effector molecule IFN-r [102]. During viral infection, DCs can be recruited to the infection site through the type I interferon mediated production of the chemokine CCL2. The recruited DCs are then activated via SIGN-R1 triggers to produce the chemokines CCL5, CXCL9, and CXCL10, which recruit $\mathrm{NK}$ and $\mathrm{T}$ cells to the infected site to kill the viruses. As a negative feedback molecule, IL-10, produced by the interacting cells, was able to limit this process [103105]. Activated NK cells may leave the lymph node, infiltrate tumors, and kill cancer cells in tumors. In contrast to $\mathrm{CD} 21^{+} \mathrm{NK}$ cells, the activated $\mathrm{CD} 2^{+} \mathrm{NK}$ cell subset produces IFN- $\gamma$. This induces DC maturation and stimulates $\mathrm{T}$ cell responses. This also kills autologous immature DCs through the CD94/NKG2A inhibitory NK receptor [102].

\section{DCs in tumor immunity and immunotherapy}

Cancer cells often escape from immune surveillance and sometimes show relative resistance to chemotherapeutic drugs. Tumors contain heterogeneous cancer cells, including tumor stem cells [106, 107], which interact with stromal cells and immune cells in the tumor microenvironment [108]. DCs, as crucial APCs, mediate tumor immunity via the activation of $\mathrm{CD}^{+}$ and $\mathrm{CD} 4^{+} \mathrm{T}$ cells (Fig. 1). In addition, exosomes expressing $\mathrm{CD} 47$ to protect themselves from phagocytosis by monocytes and macrophages have been used in tumor immunotherapy and have impressive outcomes [109]. DCs have been used for tumor immunotherapy in various kinds of preclinical and clinical studies. We categorized the included studies (Table 3), which may reflect clinical importance. We also note that viruses have been used for tumor virotherapy and immunotherapy [127-129]. Prospective studies need to be warranted to investigate the clinical benefits of cancer immunotherapy in combination with virotherapy through DC immunotherapy.

\section{DC vaccines showed great potential for tumor immunotherapy}

Tumor-specific antigens are being used to stimulate DCs. These antigens include cancer-testis or cancer-germline antigens, abnormally expressed fetal antigens, mutated antigens, overexpressed antigens, differentiation antigens, and viral antigens [130]. Culturing patient tumor cells with allogeneic-IgG-loaded DCs induced vigorous patient $\mathrm{T}$ cell responses to autologous tumor antigens, shedding light on this technique as a new potent method for tumor immunotherapy [131]. Personalized DC vaccines have induced $\mathrm{T}$ cell immunity, which targets private somatic neoantigens in certain melanoma patients and may become clinically feasible soon [132]. Personalized DC vaccines can be generated by the co-culture of autologous DCs with oxidized autologous whole tumor cell lysate (OCDC) that has been shown to significantly prolong patient survival [133]. Also, allogenic mature DCs have been made to fuse with inactive gastric cancer cells (MGC803) and cytokine-induced killing cells (CIKs), facilitating efficient, targeted immunotherapy against gastric cancer [134]. It has been found that fusion cells (FCs) in addition to CIKs can trigger tumor-specific CTLs and inhibit tumor growth in vivo. FCs can act as efficient vehicles to deliver tumor antigens systemically by activating CTL and triggering an anti-tumor immune response [134]. Mitchell and his colleagues found that a tetanus/diphtheria (Td) toxoid can induce CCL3 expression and facilitate DC migration. They deployed a DC vaccine pulsed with glioblastoma specific antigen cytomegalovirus phosphoprotein 65 (pp65), which was able to enhance anti-tumor effects [135].

\section{DCs in combination tumor immunotherapy}

Effective tumor immunotherapy requires four parts as follows: a tumor antigen targeting antibody, recombinant interleukin-2 with an extended half-life, anti-PD1, and a powerful $T$ cell vaccine [136]. These combined therapies promote immune cell infiltration and inflammatory cytokine production. Curative tumor regression is mediated mainly by $\mathrm{CD}^{+} \mathrm{T}$ cells and cross-presenting DCs, suggesting that effective treatment engages innate and adaptive immune responses to eradicate large tumors [136]. The identification of human cancer-specific antigens has led to the development of antigen-specific immunotherapy in cancer. CD47 is a transmembrane glycoprotein widely expressed on the surface of cancer cells [73], which, embedded on exosomes, limits their clearance by circulating monocytes [109]. It transmits an inhibitory signal through its receptor-the signal regulatory protein alpha (SIRP $\alpha)$ on DCs. This signal blunts antibody effector functions as an antiphagocytic ligand exploited by tumor cells [137]. The interference with CD47-SIRPa interaction synergized with tumor-specific 


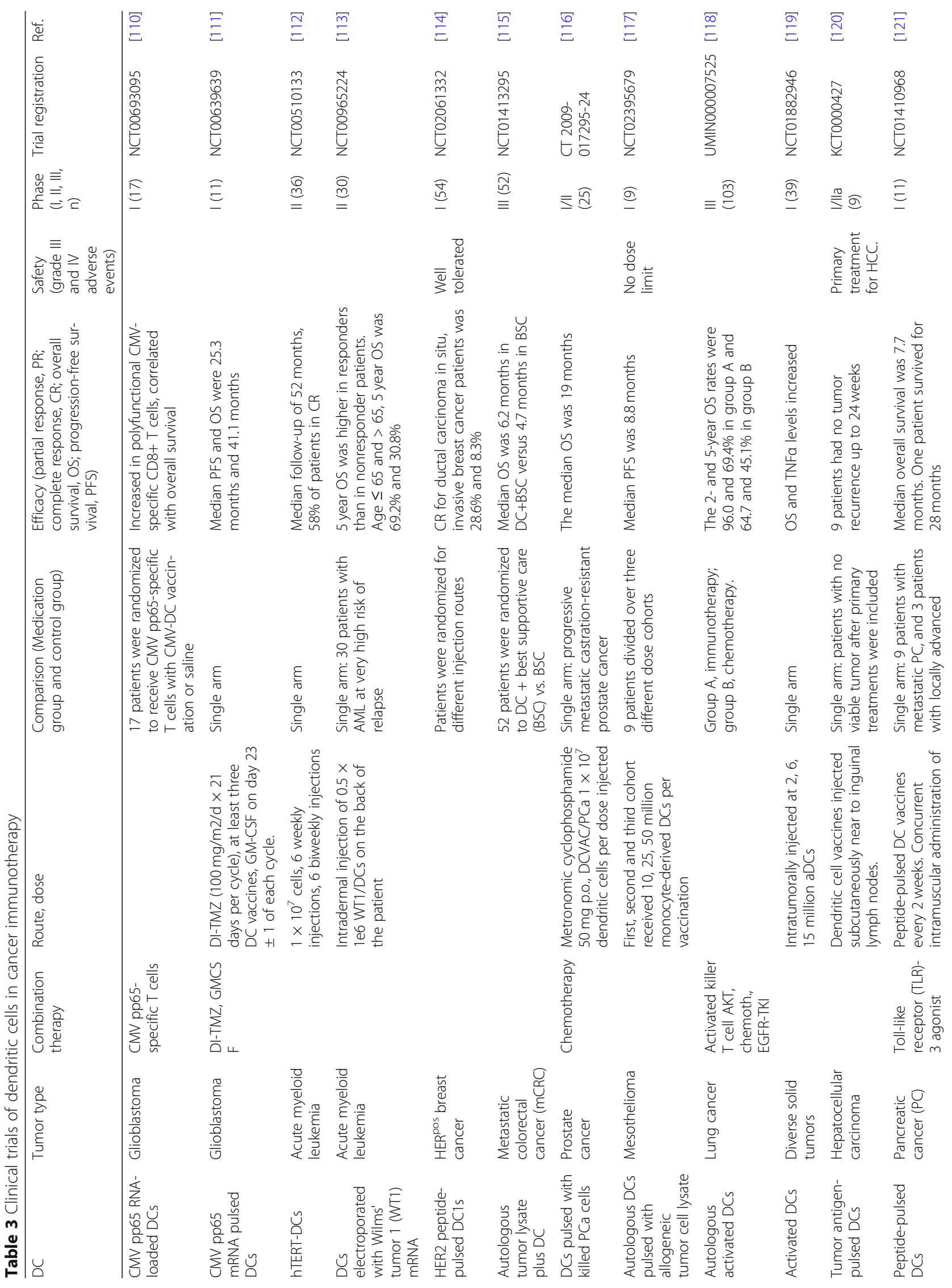




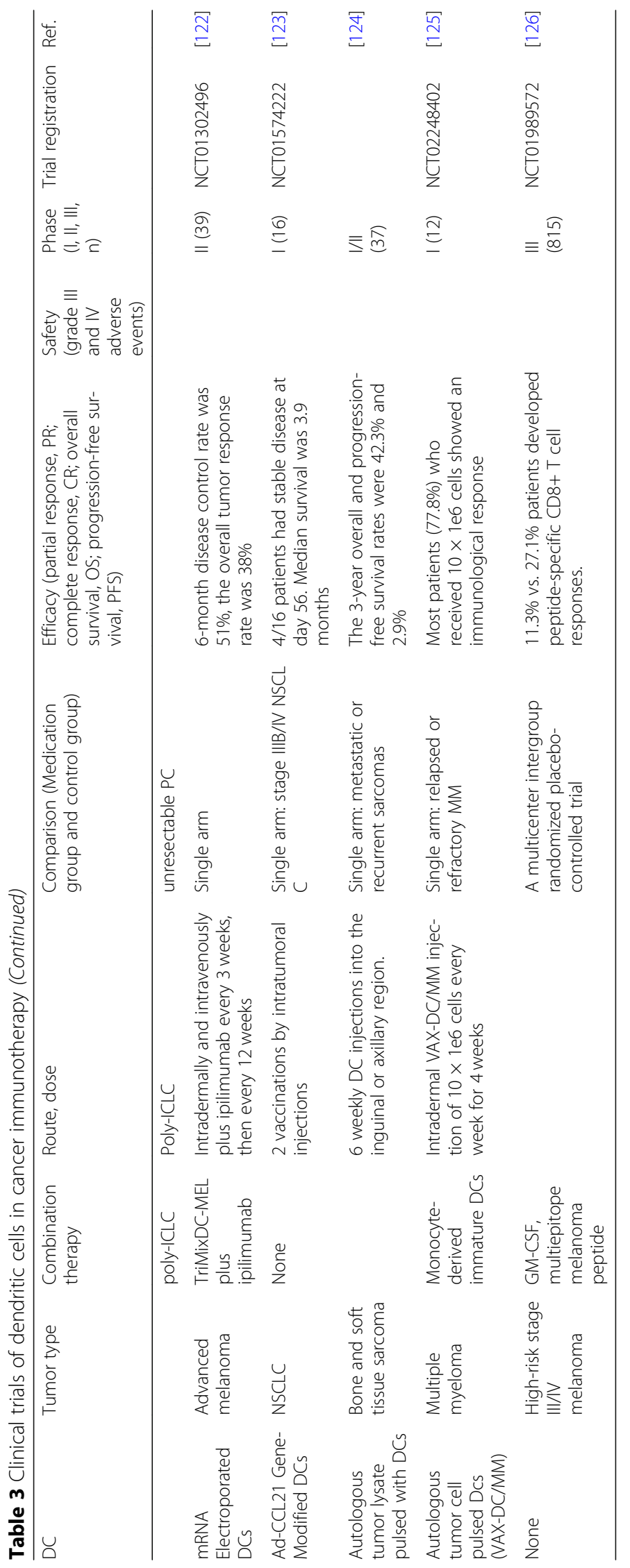


monoclonal antibodies enhanced macrophage-mediated antibody-dependent cellular phagocytosis (ADCP), leading to the elimination of human tumor xenografts in mice [137]. Exosomes harboring SIRPa variants (SIRP $\alpha-$ exosomes) were sufficient to induce augmented tumor phagocytosis, resulting in a prime, effective anti-tumor $\mathrm{T}$ cell response. This suggests that a superlative exosome-based platform has broad potential to maximize the therapeutic efficacy of membrane-associated protein therapeutics [138]. Interestingly, near-infrared photoimmunotherapy (NIR-PIT) is a localized molecular cancer therapy combining a photosensitizer-conjugated $\mathrm{mAb}$ and light energy. CD47-targeted NIR-PIT increases direct cancer cell death and phagocytosis, resulting in inhibited tumor growth and improved survival in a model of human bladder cancer [139]. A novel CD47-targeting fusion protein, termed SIRP $\alpha$ D1-Fc, was generated and found to increase the phagocytic and cytotoxic activities of macrophages against non-small cell lung cancer (NSCLC) cells [140]. Targeting both CD47 and autophagy in NSCLC xenograft models elicited enhanced anti-tumor effects, with the recruitment of macrophages, activated caspase-3, and overproduction of ROS at the tumor site [140,141].

DCs and cancer cells express PDL1 on their cell surface, which represses $\mathrm{T}$ cell activation [142]. Specific antibodies that block immune checkpoint molecules, such as the cytotoxic T lymphocyte antigen 4 (CTLA4), PDL1, and PD1 are currently licensed as therapies for various types of cancers [100, 143]. Mezzadra et al. found that CMTM4 can help CMTM6, a type-3 transmembrane protein, to reduce PDL1 ubiquitination and increase its protein half-life, enhancing the ability of PDL1-expression in tumor cells to inhibit T cells [144]. Arming Abs with IFN- $\beta$ is more potent than the first generation of Abs in controlling Ab-resistant tumors [145]. Yang et al. found that DCs were the major cell type responding directly to anti-EGFR-IFN- $\beta$ treatment by increasing antigen cross-presentation. Combined therapy with anti-EGFR-IFN- $\beta$ and PDL1 blocking completely eradicated established tumors [145]. In addition, Overacre-Delgoffe et al. found that neuropilin-1 (Nrp1)-deficient Tregs induced IFN- $\gamma$, which made intratumoral Tregs fragile and boosted anti-PD1 therapy [146]. The TLR7 antagonist Loxoribin inhibited tumor growth in xenograft models of colon cancer and lung cancer by promoting $\mathrm{CD} 4^{+} \mathrm{T}$ cell proliferation, reversing $\mathrm{CD} 4^{+} \mathrm{CD} 25^{+}$Treg-mediated suppression via $\mathrm{DCs}$ [13, 147]. DC cross-presentation can also reactivate CTL and block PDL1 induced by IFN- $\gamma$ [68]. T cell therapy needs CD40-CD40L to activate the tumor necrosis factor (TNF) and DCs to produce nitric oxide synthase 2 (NOS2) [60].

\section{DCs promote tumor immunotherapy by suppressing Treg cells}

DC-based cancer immunotherapy is a promising approach, but Treg cells in the tumor microenvironment are the biggest barrier for effective tumor immunity. Treg cells and DCs in the tumor microenvironment can mutually suppress each other [148]. DCs can suppress Treg cells but activate effector $\mathrm{T}$ (Teff) cells to enhance tumor immunity by inhibiting the p38 MAPK pathway through the DC cell surface molecule OX40L [149]. Additionally, OX40 co-stimulation by SB202190-treated mDCs (mSBDCs) inhibits the conversion of Teffs to Tregs [149]. In the tumor microenvironment, tumorassociated DCs can produce reactive oxygen species (ROS), which cause lipid peroxidation/degradation and tumor suppression. Meanwhile, the accumulation of unfolded proteins in the ER can also cause ER stress, which in turn enhances unfolded protein response (UPR), resulting in the reduced DC expression of MHC-I molecules and an impaired anti-tumor $\mathrm{T}$ cell response. This indicates that ER stress in DCs suppresses tumor immunity via MHC-I expression reduction [150, 151].

\section{Clinical trials of DC-based tumor immunotherapy}

Clinical trials of DC-related cancer immunotherapy show promising results (Table 3). These trials may be classified into DC vaccines and other DC-related trials. DC vaccines involve DCs that recognize various kinds of tumor-specific antigens or whole tumor lysates, as well as cytokine activated DCs. Other DC-related trials may not use DCs directly, but DCs are involved in their therapeutic mechanisms.

DC vaccines have been tested in multiple clinical trials to target many tumor-specific or tumor-associated antigens, including CMV pp65, telomerase, Her2, Wilms' tumor 1, and so on. Two stage I clinical pilot trials used vaccination with CMV pp65 mRNA-loaded DCs in patients with glioblastoma (GBM). Patients who received this vaccination experienced an increase in the overall frequencies of $\mathrm{IFN}^{+}, \mathrm{TNF}^{+}, \mathrm{CCL}^{+}$polyfunctional, and $\mathrm{CMV}$-specific $\mathrm{CD}^{+} \mathrm{T}$ cells, as well as long-term progression-free survival alongside overall survival [110, 111]. Telomerase activity in leukemic blasts is frequently increased among patients with high-risk acute myeloid leukemia (AML). In a stage II clinical study, the researchers found that human telomerase reverse transcriptase (hTERT)-expressing autologous DCs (hTERT-DCs) were feasible. Vaccination with hTERT-DCs appeared to be safe and may be associated with favorable recurrencefree survival in adult patients with AML [112]. DCs electroporated with Wilms' tumor 1 (WT1) messenger RNA (mRNA) were found to be an effective strategy to prevent or delay AML relapse after standard chemotherapy with the induction of WT1-specific CD8 ${ }^{+} \mathrm{T}$ cell response in a stage II clinical trial [113]. In the clinical trial anti-HER2, $\mathrm{DC} 1 \mathrm{~s}$ vaccination was a safe and immunogenic treatment to induce tumor-specific $\mathrm{T}$ cell responses in HER2 ${ }^{\text {pos }}$ breast cancer patients [114]. In another trial, Wilms' 
tumor 1 peptide-loaded DCs and OK-432 adjuvant combined with conventional chemotherapy was shown to be safe and feasible for patients with an advanced stage of head and neck squamous cell carcinoma (HNSCC) [152].

An autologous tumor lysate DC vaccine was shown to have $\mathrm{T}$ cell stimulatory capacity. It generated a tumorspecific immune response and benefitted the overall survival of metastatic colorectal cancer patients in a stage III clinical trial [115]. Autologous mature DCs pulsed with killed LNCaP prostate cancer cells (DCVAC/PCa) in addition to concomitant chemotherapy did not preclude the induction of specific anti-tumor cytotoxic $\mathrm{T}$ cells in a I/II clinical trial study [116]. Some autologous DCs generated ex vivo pulsed with tumor antigens showed limited promise in the treatment of patients with advanced cancers. In a stage I clinical trial, autologous DCs pulsed with allogeneic tumor cell lysate demonstrated that DC immunotherapy with allogeneic tumor lysate can be safe and feasible in humans [117]. The adoptive transfer of autologous activated killer $\mathrm{T}$ cells and DCs (AKT-DC) in a stage III clinical trial elevated the $\mathrm{CD} 8^{+} / \mathrm{CD} 4^{+} \mathrm{T}$ cell ratio in survivors of patients with non-small cell lung cancer [118]. Intratumoral activated DC injections in a stage I clinical trial increased the production of specific cytokines and prolonged survival as well [119].

Furthermore, in a stage I/II clinical trial, it was shown that pre-conditioning the vaccine site with a potent recall antigen such as the tetanus/diphtheria (Td) toxoid significantly improved lymph node homing and the efficacy of tumor antigen-specific DCs $[120,130]$. In one study, patients with glioblastoma were pre-conditioned with either mature DCs or Td before a vaccination with cytomegalovirus phosphoprotein 65 (pp65) mRNA pulsed DCs. The results indicated that this may represent a viable strategy to improve anti-tumor immunotherapy [130].

Other DC-related trials include the use of DCs in conjunction with the toll-like receptor (TLR)-3 agonist poly-ICLC against metastatic or locally advanced unresectable pancreatic cancer. Results showed an increased tumor-specific $\mathrm{T}$ cell population [121]. Additionally, in a stage II clinical trial, autologous monocyte-derived mRNA electroporated DCs (TriMixDC-MEL) alongside ipilimumab usage resulted in durable tumor responses in melanoma patients [122]. In a stage I clinical trial, DCs were transduced with an adenoviral (Ad) vector expressing the CCL21 gene (Ad-CCL21-DC), which induced systemic tumor antigen-specific immune responses, enhanced tumor $\mathrm{CD}^{+} \mathrm{T}$ cell infiltration, and increased tumor PDL1 expression [123].

\section{Conclusions and perspectives}

DCs are crucial sentinel cells. Educating naive $\mathrm{T}$ cells for adaptive immune responses, DCs recognize antigens, process antigens into small bioactive peptides, and form specific MHC-peptides complexes before presenting antigens to $\mathrm{T}$ cells. DCs are not only able to activate $\mathrm{T}$ cells, but they also maintain a balance among immune activation, suppression, and memorization. Thus, DCs, the mentors of $\mathrm{T}$ cells, are a key player in immune defense, surveillance, and homeostasis. Furthermore, accumulating evidence indicates that DCs are a key player in tumor immunity. DC-based tumor immunotherapy has been shown to be highly effective in preclinical studies and clinical trials. DCs can specifically recognize, process, and present diverse and heterogeneous cancer antigens, as well as activate $\mathrm{T}$ cells specifically to overcome drug resistance caused by cancer cell heterogeneity. DC-based tumor immunotherapy has shown great potential in a wide variety of tumors.

The increasing applications of new technologies and hypotheses to DC research will likely reveal more insights in our fundamental understanding of DC biology. Future works can easily promote the development of new strategies for DC-based tumor immunotherapy, and we believe that DC-based tumor immunotherapy holds great promise for a cure to cancer in future.

\section{Abbreviations}

DCs: Dendritic cells; APCs: Antigen presenting cells; IncRNAs: Long noncoding RNAs; HSCs: Hematopoietic stem cells; MHC: Major histocompatibility complex; CTL: Cytotoxic T lymphocyte; PAMPs: Pathogen-associated molecular patterns; DAMPs: Danger-associated molecular patterns; PRRs: Pattern recognition receptors; CLRs: C-type lectins receptors; GPCRs: FPRs are G protein-coupled receptors; NLRP3: Pyrin domaincontaining 3; ITAM: Immune receptor tyrosine-based activation motif; ITIM: Immune receptor tyrosine-based inhibitory motif; TRIM21: Tripartite motif-containing protein 21; TGN: Trans-Golgi network; BRS: Basic residue-rich sequence; W: Vaccinia virus; HCC: Hepatocellular carcinoma;

IDO1: Indoleamine 2, 3-dioxygenases; ER: Endoplasmic reticulum; OCDC: Coculture of autologous DCs with oxidized autologous whole tumor cell lysate; ADCP: Antibody-dependent cellular phagocytosis; NIR-PIT: Near-infrared photoimmunotherapy; NSCLC: Non-small cell lung cancer; HNSCC: Head and neck squamous cell carcinoma

\section{Acknowledgements}

We thank Professor Jixi Zhong, Professor Jun-Yan Han, and Dr. Yu Amanda Guo for their critical expert review of the manuscript.

\section{Authors' contributions \\ WYY wrote and edited the manuscript, collected the related literature, and finished the figures and tables. WWX, WXW, XCP, DW, NL, JTC, YNL, CSZ, YX, ZWM, QZ, and HWX revised and edited the manuscript. YX, ZWM, QZ, and HWX provided feedback and guidance. All authors approved the final manuscript.}

\section{Funding}

This work was supported by National Natural Science Foundation of China (81872412 to XHW, 81602303 to XY, 31771273 to QZ), Natural Science Foundation of Hubei Province (2019CFB591 to Z.M.), Guangzhou Key Medical Discipline Construction Project (CSZ), Yangtze University Fellowship to WYY, and Special Financial Foundation of Shenzhen (20180129171138130,

JCYJ20180307163444601 to QZ).

Availability of data and materials Not applicable. 


\section{Ethics approval and consent to participate}

Not applicable.

\section{Consent for publication}

Not applicable.

\section{Competing interests}

The authors declare that they have no conflict of interest relating to the publication of this manuscript.

\section{Author details}

${ }^{1}$ State Key Laboratory of Respiratory Disease, Affiliated Cancer Hospital \& Institute of Guangzhou Medical University, Guangzhou 510095, China. ${ }^{2}$ Laboratory of Oncology, Center for Molecular Medicine, School of Basic Medicine, Faculty of Medicine, Yangtze University, 1 Nanhuan Road, Jingzhou 434023, Hubei, China. ${ }^{3}$ Department of Biochemistry and Molecular Biology, School of Basic Medicine, Faculty of Medicine, Yangtze University, Jingzhou 434023, Hubei, China. ${ }^{4}$ Department of Gynaecology, Comprehensive Cancer Center, Hannover Medical School, 30625 Hannover, Germany. ${ }^{5}$ Stanford University, Stanford, CA 94305, USA. ${ }^{6}$ Department of Laboratory Medicine, School of Basic Medicine, Faculty of Medicine, Yangtze University, 1 Nanhuan Road, Jingzhou 434023, Hubei, China. 'Department of Pathophysiology, School of Basic Medicine, Faculty of Medicine, Yangtze University, Jingzhou 434023, Hubei, China. ${ }^{8}$ Department of Medical Imaging, School of Basic Medicine, Faculty of Medicine, Yangtze University, Jingzhou 434023, Hubei, China. ${ }^{9}$ Department of Oncology, First Affiliated Hospital of Yangtze University, Jingzhou, Hubei, China. ${ }^{10}$ Institute for Infectious Diseases and Endemic Diseases Prevention and Control, Beijing Center for Diseases Prevention and Control, Beijing 100013, China. ${ }^{11}$ State Key Laboratory of Biocontrol, School of Life Sciences, Sun Yat-sen University, Guangzhou 510275, China. ${ }^{12}$ Institute of Sun Yat-sen University in Shenzhen, Shenzhen, China. ${ }^{13}$ People's Hospital of Lianjiang, Lianjiang 524400, Guangdong, China.

Received: 18 April 2020 Accepted: 20 July 2020

Published online: 03 August 2020

\section{References}

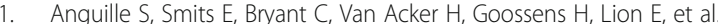
Dendritic cells as pharmacological tools for cancer immunotherapy. Pharmacol Rev. 2015;67(4):731-53.

2. Fang P, Li X, Dai J, Cole L, Camacho JA, Zhang Y, et al. Immune cell subset differentiation and tissue inflammation. J Hematol Oncol. 2018;11(1):97.

3. Bordon Y. Dendritic cells: sorting, sorted! Nat Rev Immunol. 2016;16(11):657.

4. Benteyn D, Heirman C, Bonehill A, Thielemans K, Breckpot K. mRNA-based dendritic cell vaccines. Expert Rev Vaccines. 2015;14(2):161-76.

5. Leone DA, Rees AJ, Kain R. Dendritic cells and routing cargo into exosomes. Immunol Cell Biol. 2018.

6. Russo E, Teijeira A, Vaahtomeri K, Willrodt AH, Bloch JS, Nitschke M, et al. Intralymphatic CCL21 promotes tissue egress of dendritic cells through afferent lymphatic vessels. Cell Rep. 2016;14(7):1723-34.

7. Pearce EJ. Everts B: dendritic cell metabolism. Nat Rev Immunol. 2015;15(1): $18-29$.

8. Vander Lugt B, Khan AA, Hackney JA, Agrawal S, Lesch J, Zhou M, et al. Transcriptional programming of dendritic cells for enhanced MHC class II antigen presentation. Nat Immunol. 2014;15(2):161-7.

9. Malinverno C, Corallino S, Giavazzi F, Bergert M, Li Q, Leoni M, Disanza A, et al. Endocytic reawakening of motility in jammed epithelia. Nat Mater. 2017:16(5):587-96.

10. Schreibelt G, Klinkenberg LJ, Cruz LJ, Tacken PJ, Tel J, Kreutz M, et al. The Ctype lectin receptor CLEC9A mediates antigen uptake and (cross-) presentation by human blood BDCA3+ myeloid dendritic cells. Blood. 2012; 119(10):2284-92

11. Liu X, Pu Y, Cron K, Deng L, Kline J, Frazier WA, et al. CD47 blockade triggers T cell-mediated destruction of immunogenic tumors. Nat Med. 2015;21(10): 1209-15.

12. Stappers MHT, Clark AE, Aimanianda V, Bidula S, Reid DM, Asamaphan P, et al. Recognition of DHN-melanin by a C-type lectin receptor is required for immunity to Aspergillus. Nature. 2018;555(7696):382-6.

13. Wang C, Zhou Q, Wang X, Wu X, Chen X, Li J, et al. The TLR7 agonist induces tumor regression both by promoting CD4(+)T cells proliferation and by reversing T regulatory cell-mediated suppression via dendritic cells. Oncotarget. 2015;6(3):1779-89.

14. Chen ST, Li FJ, Hsu TY, Liang SM, Yeh YC, Liao WY, et al. CLEC5A is a critical receptor in innate immunity against Listeria infection. Nat Commun. 2017; 8(1):299.

15. Dos Santos A, Hadjivasiliou A, Ossa F, Lim NK, Turgut A, Taylor ME, et al. Oligomerization domains in the glycan-binding receptors DC-SIGN and DC-SIGN R: Sequence variation and stability differences. Protein Sci. 2017;26(2):306-16.

16. Jarvis CM, Zwick DB, Grim JC, Alam MM, Prost LR, Gardiner JC, et al. Antigen structure affects cellular routing through DC-SIGN. Proc Natl Acad Sci U S A. 2019;116(30):14862-7.

17. Hossain MK, Wall KA. Use of dendritic cell receptors as targets for enhancing anti-cancer immune responses. Cancers (Basel). 2019;11:3.

18. Gringhuis SI, Kaptein TM, Wevers BA, Mesman AW, Geijtenbeek TB. Fucosespecific DC-SIGN signalling directs T helper cell type-2 responses via IKKepsilon- and CYLD-dependent Bcl3 activation. Nat Commun. 2014;5:3898.

19. Gringhuis SI, Kaptein TM, Wevers BA, van der Vlist M, Klaver EJ, van Die I, et al. Fucose-based PAMPs prime dendritic cells for follicular T helper cell polarization via DC-SIGN-dependent IL-27 production. Nat Commun. 2014;5: 5074

20. Chao PZ, Hsieh MS, Cheng CW, Hsu TJ, Lin YT, Lai CH, et al. Dendritic cells respond to nasopharygeal carcinoma cells through annexin A2-recognizing DC-SIGN. Oncotarget. 2015;6(1):159-70.

21. Tanigaki K, Sundgren N, Khera A, Vongpatanasin W, Mineo C, Shaul PW. Fcgamma receptors and ligands and cardiovascular disease. Circ Res. 2015; 116(2):368-84

22. Chen K, Bao Z, Gong W, Tang P, Yoshimura T, Wang J. Regulation of inflammation by members of the formyl-peptide receptor family. J Autoimmun. 2017:85:64-77.

23. He H, Ye R. The formyl peptide receptors: diversity of ligands and mechanism for recognition. Molecules. 2017;22:3.

24. Prevete $N$, de Paulis A, Sgambato D, Melillo R, D'Argenio G, Romano L, et al. Role of formyl peptide receptors in gastrointestinal healing. Curr Pharm Des 2018.

25. Stepniewski TM, Filipek S. Non-peptide ligand binding to the formyl peptide receptor FPR2--a comparison to peptide ligand binding modes. Bioorg Med Chem. 2015:23(14):4072-81.

26. Yousif AM, Ingangi V, Merlino F, Brancaccio D, Minopoli M, Bellavita R, et al. Urokinase receptor derived peptides as potent inhibitors of the formyl peptide receptor type 1-triggered cell migration. Eur J Med Chem. 2018;143: 348-60.

27. Wolf AJ, Reyes CN, Liang W, Becker C, Shimada K, Wheeler ML, et al. Hexokinase is an innate immune receptor for the detection of bacterial peptidoglycan. Cell. 2016;166(3):624-36.

28. Yeon SH, Yang G, Lee HE, Lee JY. Oxidized phosphatidylcholine induces the activation of NLRP3 inflammasome in macrophages. J Leukoc Biol. 2017; 101(1):205-15

29. Feng S, Fox D, Man SM: Mechanisms of gasdermin family members in inflammasome signaling and cell death. J Mol Biol 2018, 430(18 Pt B):30683080.

30. Proff J, Brey CU, Ensser A, Holter W, Lehner M. Turning the tables on cytomegalovirus: targeting viral Fc receptors by CARs containing mutated CH2-CH3 lgG spacer domains. J Transl Med. 2018;16(1):26.

31. van de Winkel JG, Anderson CL. Biology of human immunoglobulin G FC receptors. J Leukoc Biol. 1991;49(5):511-24.

32. Zhang D, Whitaker B, Derebe MG, Chiu ML. FcgammaRIl-binding centyrins mediate agonism and antibody-dependent cellular phagocytosis when fused to an anti-OX40 antibody. MAbs. 2018;10(3):463-75.

33. Stapleton $\mathrm{N}$, Einarsdóttir $\mathrm{H}$, Stemerding A, Vidarsson $\mathrm{G}$. The multiple facets of FCRn in immunity. Immunol Rev. 2015;268(1):253-68.

34. Unanue ER, Turk V, Neefjes J. Variations in MHC class II antigen processing and presentation in health and disease. Annu Rev Immunol. 2016;34:265-97.

35. Sand KM, Bern M, Nilsen J, Dalhus B, Gunnarsen KS, Cameron J, et al. Interaction with both domain I and III of albumin is required for optimal $\mathrm{pH}$-dependent binding to the neonatal Fc receptor (FcRn). J Biol Chem. 2014;289(50):34583-94

36. Spassov VZ, Yan L. pH-selective mutagenesis of protein-protein interfaces: in silico design of therapeutic antibodies with prolonged half-life. Proteins. 2013:81(4):704-14

37. Cervenak J, Kurrle R, Kacskovics I. Accelerating antibody discovery using transgenic animals overexpressing the neonatal Fc receptor as a result of augmented humoral immunity. Immunol Rev. 2015;268(1):269-87. 
38. Baker K, Rath T, Pyzik M, Blumberg RS. The role of FcRn in antigen presentation. Front Immunol. 2014;5.

39. Balasubbramanian D, Gelston CAL, Mitchell BM, Chatterjee P. Toll-like receptor activation, vascular endothelial function, and hypertensive disorders of pregnancy. Pharmacol Res. 2017;121:14-21.

40. Baratin M, Foray C, Demaria O, Habbeddine M, Pollet E, Maurizio J, et al. Homeostatic NF-kappaB signaling in steady-state migratory dendritic cells regulates immune homeostasis and tolerance. Immunity. 2015;42(4):627-39.

41. Mann M, Mehta A, Zhao JL, Lee K, Marinov GK, Garcia-Flores Y, et al. An NFkappaB-microRNA regulatory network tunes macrophage inflammatory responses. Nat Commun. 2017;8(1):851.

42. Majer O, Liu B, Kreuk LSM, Krogan N, Barton GM. UNC93B1 recruits syntenin1 to dampen TLR7 signalling and prevent autoimmunity. Nature. 2019; 575(7782):366-70.

43. Wang W, Deng Z, Wu H, Zhao Q, Li T, Zhu W, et al. A small secreted protein triggers a TLR2/4-dependent inflammatory response during invasive Candida albicans infection. Nat Commun. 2019:10(1):1015.

44. Vidya MK, Kumar VG, Sejian V, Bagath M, Krishnan G, Bhatta R. Toll-like receptors: significance, ligands, signaling pathways, and functions in mammals. Int Rev Immunol. 2018;37(1):20-36.

45. Feng $Y, M u R$, Wang $Z$, Xing $P$, Zhang J, Dong $L$, et al. A toll-like receptor agonist mimicking microbial signal to generate tumor-suppressive macrophages. Nat Commun. 2019;10(1):2272.

46. Yin C, Kim Y, Argintaru D, Heit B. Rab17 mediates differential antigen sorting following efferocytosis and phagocytosis. Cell Death Dis. 2016;7(12):e2529.

47. Chen ZH, Yu YP, Zuo ZH, Nelson JB, Michalopoulos GK, Monga S, et al. Targeting genomic rearrangements in tumor cells through Cas9-mediated insertion of a suicide gene. Nat Biotechnol. 2017;35(6):543-50.

48. Kambayashi T, Laufer TM. Atypical MHC class II-expressing antigenpresenting cells: can anything replace a dendritic cell? Nat Rev Immunol. 2014;14(11):719-30.

49. Burrows SR, Rossjohn J, McCluskey J. Have we cut ourselves too short in mapping CTL epitopes? Trends Immunol. 2006;27(1):11-6.

50. Roche PA, Furuta K. The ins and outs of MHC class II-mediated antigen processing and presentation. Nat Rev Immunol. 2015;15(4):203-16.

51. Blum JS, Wearsch PA, Cresswell P. Pathways of antigen processing. Annu Rev Immunol. 2013;31:443-73.

52. Alexander JJ, Chaves LD, Chang A, Jacob A, Ritchie M, Quigg RJ. CD11b is protective in complement-mediated immune complex glomerulonephritis. Kidney Int. 2015;87(5):930-9.

53. Sercarz EE, Maverakis E. Mhc-guided processing: binding of large antigen fragments. Nat Rev Immunol. 2003;3(8):621-9.

54. Rausch MP, Hastings KT: Diverse cellular and organismal functions of the lysosomal thiol reductase GILT. Mol Immunol 2015, 68(2 Pt A):124-128.

55. Nikbakht Brujeni G, Khosravi M. Molecular characterization of chicken class II transactivator gene. Immunogenetics. 2015;67(1):39-49.

56. Oliva K, Cavanaugh J, Cobb B. Antibody receptors steal the sweet spotlight. J Biol Chem. 2018;293(10):3490-1.

57. Rupanagudi KV, Kulkarni OP, Lichtnekert J, Darisipudi MN, Mulay SR, Schott B, et al. Cathepsin S inhibition suppresses systemic lupus erythematosus and lupus nephritis because cathepsin $S$ is essential for MHC class II-mediated CD4 T cell and B cell priming. Ann Rheum Dis. 2015;74(2):452-63

58. Costantino CM, Hang HC, Kent SC, Hafler DA, Ploegh HL. Lysosomal cysteine and aspartic proteases are heterogeneously expressed and act redundantly to initiate human invariant chain degradation. J Immunol. 2008;180(5):2876-85.

59. Samie M, Cresswell P. The transcription factor TFEB acts as a molecular switch that regulates exogenous antigen-presentation pathways. Nat Immunol. 2015;16(7):729-36.

60. Marigo I, Zilio S, Desantis G, Mlecnik B, Agnellini AH, Ugel S, et al. T cell cancer therapy requires CD40-CD40L activation of tumor necrosis factor and inducible nitric-oxide-synthase-producing dendritic cells. Cancer cell. 2016; 30(4):651.

61. Ding Y, Guo Z, Liu Y, Li X, Zhang Q, Xu X, et al. The lectin Siglec-G inhibits dendritic cell cross-presentation by impairing MHC class I-peptide complex formation. Nat Immunol. 2016;17(10):1167-75.

62. Akram A, Inman RD. Immunodominance: a pivotal principle in host response to viral infections. Clin Immunol. 2012;143(2):99-115.

63. Nair-Gupta P, Baccarini A, Tung N, Seyffer F, Florey O, Huang Y, et al. TLR signals induce phagosomal MHC-I delivery from the endosomal recycling compartment to allow cross-presentation. Cell. 2014;158(3):506-21.
64. Avalos AM, Ploegh HL. Early BCR events and antigen capture, processing, and loading on MHC class II on B cells. Front Immunol. 2014:5:92.

65. Cai E, Marchuk K, Beemiller P, Beppler C, Rubashkin MG, Weaver VM, et al. Visualizing dynamic microvillar search and stabilization during ligand detection by T cells. Science. 2017;356:6338.

66. Guo X, Yan C, Li H, Huang W, Shi X, Huang M, et al. Lipid-dependent conformational dynamics underlie the functional versatility of T-cell receptor. Cell Res. 2017;27(4):505-25.

67. Rossjohn J, Gras S, Miles JJ, Turner SJ, Godfrey DI, McCluskey J. T cell antigen receptor recognition of antigen-presenting molecules. Annu Rev Immunol. 2015;33:169-200.

68. Liu Z, Ravindranathan R, Kalinski P, Guo ZS, Bartlett DL. Rational combination of oncolytic vaccinia virus and PD-L1 blockade works synergistically to enhance therapeutic efficacy. Nat Commun. 2017;8:14754.

69. Buchholz VR, Schumacher TN, Busch DH. T cell date at the single-cell level. Annu Rev Immunol. 2016;34:65-92.

70. Wucherpfennig KW, Gagnon E, Call MJ, Huseby ES, Call ME. Structural biology of the T-cell receptor: insights into receptor assembly, ligand recognition, and initiation of signaling. Cold Spring Harb Perspect Biol. 2010 2(4):a005140.

71. Dave VP. Hierarchical role of $\mathrm{CD} 3$ chains in thymocyte development. Immunol Rev. 2009;232(1):22-33.

72. Moura Rosa P, Gopalakrishnan N, Ibrahim H, Haug M, Halaas O. The intercell dynamics of T cells and dendritic cells in a lymph node-on-a-chip flow device. Lab Chip. 2016;16(19):3728-40.

73. Liu X, Kwon H, Li Z, Fu YX. Is CD47 an innate immune checkpoint for tumor evasion? J Hematol Oncol. 2017;10(1):12.

74. Eickhoff S, Brewitz A, Gerner MY, Klauschen F, Komander K, Hemmi H, et al. Robust anti-viral immunity requires multiple distinct $\mathrm{T}$ cell-dendritic cell interactions. Cell. 2015;162(6):1322-37.

75. Garib FY, Rizopulu AP. T-regulatory cells as part of strategy of immune evasion by pathogens. Biochemistry (Mosc). 2015;80(8):957-71.

76. Tkach M, Kowal J, Zucchetti AE, Enserink L, Jouve M, Lankar D, et al. Qualitative differences in T-cell activation by dendritic cell-derived extracellular vesicle subtypes. EMBO J. 2017;36(20):3012-28.

77. Pitt JM, Andre F, Amigorena S, Soria JC, Eggermont A, Kroemer G, et al. Dendritic cell-derived exosomes for cancer therapy. J Clin Invest. 2016; 126(4):1224-32.

78. Wei G, Jie Y, Haibo L, Chaoneng W, Dong H, Jianbing Z, et al. Dendritic cells derived exosomes migration to spleen and induction of inflammation are regulated by CCR7. Sci Rep. 2017;7:42996.

79. Rao Q, Zuo B, Lu Z, Gao X, You A, Wu C, et al. Tumor-derived exosomes elicit tumor suppression in murine hepatocellular carcinoma models and humans in vitro. Hepatology. 2016;64(2):456-72.

80. Lu Z, Zuo B, Jing R, Gao X, Rao Q, Liu Z, et al. Dendritic cell-derived exosomes elicit tumor regression in autochthonous hepatocellular carcinoma mouse models. J Hepatol. 2017;67(4):739-48.

81. Lai JH, Luo SF, Ho L. Targeting the CD40-CD154 signaling pathway for treatment of autoimmune arthritis. Cells. 2019;8:8.

82. Pasqual G, Chudnovskiy A, Tas JMJ, Agudelo M, Schweitzer LD, Cui A, et al. Monitoring $T$ cell-dendritic cell interactions in vivo by intercellular enzymatic labelling. Nature. 2018;553(7689):496-500.

83. Wolf D, Ley K. Immunity and inflammation in atherosclerosis. Circ Res. 2019; 124(2):315-27.

84. Winkels $\mathrm{H}$, Ehinger $\mathrm{E}$, Vassallo M, Buscher $\mathrm{K}$, Dinh HQ Kobiyama K et al. Atlas of the immune cell repertoire in mouse atherosclerosis defined by single-cell RNA-sequencing and mass cytometry. Circ Res. 2018;122(12):1675-88.

85. Gu Y, Liu Y, Fu L, Zhai L, Zhu J, Han Y, et al. Tumor-educated B cells selectively promote breast cancer lymph node metastasis by HSPA4targeting IgG. Nat Med. 2019.

86. Gu Y, Liu Y, Fu L, Zhai L, Zhu J, Han Y, et al. Tumor-educated B cells selectively promote breast cancer lymph node metastasis by HSPA4targeting lgG. Nat Med. 2019;25(2):312-22.

87. Bournazos S, Wang T, Dahan R, Maamary J, Ravetch J. Signaling by antibodies: recent progress. Annu Rev Immunol. 2017;35:285-311.

88. Wu W, He C, Liu C, Cao AT, Xue X, Evans-Marin HL, et al. miR-10a inhibits dendritic cell activation and Th1/Th17 cell immune responses in IBD. Gut. 2015;64(11):1755-64.

89. Wendeln AC, Degenhardt K, Kaurani L, Gertig M, Ulas T, Jain G, et al. Innate immune memory in the brain shapes neurological disease hallmarks. Nature. 2018:556(7701):332-8. 
90. Halim TY, Hwang YY, Scanlon ST, Zaghouani H, Garbi N, Fallon PG, et al. Group 2 innate lymphoid cells license dendritic cells to potentiate memory TH2 cell responses. Nat Immunol. 2016;17(1):57-64.

91. Walker J, McKenzie A. T2 cell development and function. Nat Rev Immunol. 2018;18(2):121-33

92. DiLillo DJ, Ravetch JV. Differential Fc-receptor engagement drives an antitumor vaccinal effect. Cell. 2015;161(5):1035-45.

93. Zhang Z, Li J, Zheng W, Zhao G, Zhang H, Wang X, et al. Peripheral lymphoid volume expansion and maintenance are controlled by gut microbiota via RALDH+ dendritic cells. Immunity. 2016;44(2):330-42.

94. Zanoni I, Tan Y, Di Gioia M, Broggi A, Ruan J, Shi J, et al. An endogenous caspase-11 ligand elicits interleukin-1 release from living dendritic cells. Science. 2016;352(6290):1232-6.

95. Zitvogel L, Kroemer G. CD103+ dendritic cells producing interleukin-12 in anticancer immunosurveillance. Cancer cell. 2014;26(5):591-3.

96. Roberts EW, Broz ML, Binnewies M, Headley MB, Nelson AE, Wolf DM, et al. Critical role for CD103(+)/CD141(+) dendritic cells bearing CCR7 for tumor antigen trafficking and priming of $T$ cell immunity in melanoma. Cancer cell. 2016;30(2):324-36.

97. Weist BM, Kurd N, Boussier J, Chan SW, Robey EA. Thymic regulatory T cell niche size is dictated by limiting IL-2 from antigen-bearing dendritic cells and feedback competition. Nat Immunol. 2015;16(6):635-41.

98. Meyers DE, Hill WF, Suo A, Jimenez-Zepeda V, Cheng T, Nixon NA. Aplastic anemia secondary to nivolumab and ipilimumab in a patient with metastatic melanoma: a case report. Exp Hematol Oncol. 2018;7:6.

99. Uto T, Fukaya T, Takagi H, Arimura K, Nakamura T, Kojima N, et al. Clec4A4 is a regulatory receptor for dendritic cells that impairs inflammation and T-cell immunity. Nat Commun. 2016;7:11273.

100. Laidlaw BJ, Craft JE, Kaech SM. The multifaceted role of CD4(+) T cells in CD8(+) T cell memory. Nat Rev Immunol. 2016;16(2):102-11.

101. Liu M, Wang X, Wang L, Ma X, Gong Z, Zhang S, et al. Targeting the IDO1 pathway in cancer: from bench to bedside. J Hematol Oncol. 2018:11(1):100.

102. Harizi H. Reciprocal crosstalk between dendritic cells and natural killer cells under the effects of PGE2 in immunity and immunopathology. Cell Mol Immunol. 2013;10(3):213-21.

103. Mingozzi F, Spreafico R, Gorletta T, Cigni C, Di Gioia M, Caccia M, et al. Prolonged contact with dendritic cells turns lymph node-resident NK cells into anti-tumor effectors. EMBO Mol Med. 2016;8(9):1039-51.

104. Palomino-Segura M, Perez L, Farsakoglu Y, Virgilio T, Latino I, D'Antuono R, et al. Protection against influenza infection requires early recognition by inflammatory dendritic cells through C-type lectin receptor SIGN-R1. Nat Microbiol. 2019;4(11):1930-40.

105. Chong WP, van Panhuys N, Chen J, Silver PB, Jittayasothorn Y, Mattapalli MJ, et al. NK-DC crosstalk controls the autopathogenic Th17 response through an innate IFN-gamma-IL-27 axis. J Exp Med. 2015;212(10):1739-52.

106. Xin HW, Ambe CM, Hari DM, Wiegand GW, Miller TC, Chen JQ, et al. Labelretaining liver cancer cells are relatively resistant to sorafenib. Gut. 2013; 62(12):1777-86.

107. Xin HW, Hari DM, Mullinax JE, Ambe CM, Koizumi T, Ray S, et al. Tumorinitiating label-retaining cancer cells in human gastrointestinal cancers undergo asymmetric cell division. Stem Cells. 2012;30(4):591-8.

108. Liu Y, Yu C, Wu Y, Sun X, Su Q, You C, et al. CD44(+) fibroblasts increases breast cancer cell survival and drug resistance via IGF2BP3-CD44-IGF2 signalling. J Cell Mol Med. 2017;21(9):1979-88.

109. Kamerkar S, LeBleu VS, Sugimoto H, Yang S, Ruivo CF, Melo SA, et al. Exosomes facilitate therapeutic targeting of oncogenic KRAS in pancreatic cancer. Nature. 2017;546(7659):498-503.

110. Reap EA, Suryadevara CM, Batich KA, Sanchez-Perez L, Archer GE, Schmittling RJ, et al. Dendritic cells enhance polyfunctionality of adoptively transferred T cells that target cytomegalovirus in glioblastoma. Cancer Res. 2018;78(1):256-64

111. Batich KA, Reap EA, Archer GE, Sanchez-Perez L, Nair SK, Schmittling RJ, et al. Long-term survival in glioblastoma with cytomegalovirus pp65targeted vaccination. Clin Cancer Res. 2017;23(8):1898-909.

112. Khoury HJ, Collins RH Jr, Blum W, Stiff PS, Elias L, et al. Immune responses and long-term disease recurrence status after telomerase-based dendritic cell immunotherapy in patients with acute myeloid leukemia. Cancer. 2017; 123(16):3061-72.

113. Anguille S, Van de Velde AL, Smits EL, Van Tendeloo VF, Juliusson G, Cools $N$, et al. Dendritic cell vaccination as postremission treatment to prevent or delay relapse in acute myeloid leukemia. Blood. 2017;130(15):1713-21.
114. Lowenfeld L, Mick R, Datta J, Xu S, Fitzpatrick E, Fisher CS, et al. Dendritic cell vaccination enhances immune responses and induces regression of HER2(pos) DCIS independent of route: results of randomized selection design trial. Clin Cancer Res. 2017;23(12):2961-71.

115. Caballero-Banos M, Benitez-Ribas D, Tabera J, Varea S, Vilana R, Bianchi L, et al. Phase II randomised trial of autologous tumour lysate dendritic cell plus best supportive care compared with best supportive care in pretreated advanced colorectal cancer patients. Eur J Cancer. 2016;64:167-74.

116. Podrazil M, Horvath R, Becht E, Rozkova D, Bilkova P, Sochorova K, et al. Phase I/II clinical trial of dendritic-cell based immunotherapy (DCVAC/PCa) combined with chemotherapy in patients with metastatic, castrationresistant prostate cancer. Oncotarget. 2015;6(20):18192-205.

117. Aerts J, de Goeje PL, Cornelissen R, Kaijen-Lambers MEH, Bezemer K, van der Leest $\mathrm{CH}$, et al. Autologous dendritic cells pulsed with allogeneic tumor cell lysate in mesothelioma: from mouse to human. Clin Cancer Res. 2018;24(4):766-76.

118. Kimura H, Matsui Y, Ishikawa A, Nakajima T, lizasa T. Randomized controlled phase III trial of adjuvant chemoimmunotherapy with activated cytotoxic T cells and dendritic cells from regional lymph nodes of patients with lung cancer. Cancer Immunol Immunother. 2018:67(8):1231-8.

119. Subbiah V, Murthy R, Hong DS, Prins RM, Hosing C, Hendricks K, et al. Cytokines produced by dendritic cells administered intratumorally correlate with clinical outcome in patients with diverse cancers. Clin Cancer Res. 2018;24(16):3845-56.

120. Lee JH, Lee $Y$, Lee M, Heo MK, Song JS, Kim KH, et al. A phase I/lla study of adjuvant immunotherapy with tumour antigen-pulsed dendritic cells in patients with hepatocellular carcinoma. Br J Cancer. 2015;113(12):1666-76.

121. Mehrotra S, Britten CD, Chin S, Garrett-Mayer E, Cloud CA, Li M, et al. Vaccination with poly(IC:LC) and peptide-pulsed autologous dendritic cells in patients with pancreatic cancer. J Hematol Oncol. 2017;10(1):82.

122. Wilgenhof S, Corthals J, Heirman C, van Baren N, Lucas S, Kvistborg P, et al. Phase II study of autologous monocyte-derived mRNA electroporated dendritic cells (TriMixDC-MEL) plus ipilimumab in patients with pretreated advanced melanoma. J Clin Oncol. 2016;34(12):1330-8.

123. Lee JM, Lee MH, Garon E, Goldman JW, Salehi-Rad R, Baratelli FE, et al. Phase I trial of intratumoral injection of CCL21 gene-modified dendritic cells in lung cancer elicits tumor-specific immune responses and CD8(+) T-cell infiltration. Clin Cancer Res. 2017;23(16):4556-68.

124. Miwa S, Nishida H, Tanzawa Y, Takeuchi A, Hayashi K, Yamamoto N, et al. Phase 1/2 study of immunotherapy with dendritic cells pulsed with autologous tumor lysate in patients with refractory bone and soft tissue sarcoma. Cancer. 2017;123(9):1576-84.

125. Jung $\mathrm{SH}$, Lee HJ, Lee $Y K$, Yang DH, Kim HJ, Rhee JH, et al. A phase I clinical study of autologous dendritic cell therapy in patients with relapsed or refractory multiple myeloma. Oncotarget. 2017;8(25):41538-48,

126. Butterfield LH, Zhao F, Lee S, Tarhini AA, Margolin KA, White RL, et al. Immune correlates of GM-CSF and melanoma peptide vaccination in a randomized trial for the adjuvant therapy of resected high-risk melanoma (E4697). Clin Cancer Res. 2017;23(17):5034-43.

127. Wang $D$, Wang $X W$, Peng XC, Xiang $Y$, Song SB, Wang $Y Y$, et al. CRISPR/Cas 9 genome editing technology significantly accelerated herpes simplex virus research. Cancer Gene Ther. 2018:25(5-6):93-105.

128. Wu ZJ, Tang FR, Ma ZW, Peng XC, Xiang Y, Zhang Y, et al. Oncolytic viruses for tumor precision imaging and radiotherapy. Hum Gene Ther. 2018;29(2): 204-22.

129. Zhang W, Bao L, Yang S, Qian Z, Dong M, Yin L, et al. Tumor-selective replication herpes simplex virus-based technology significantly improves clinical detection and prognostication of viable circulating tumor cells. Oncotarget. 2016;7(26):39768-83.

130. Mitchell DA, Batich KA, Gunn MD, Huang MN, Sanchez-Perez L, Nair SK, et al. Tetanus toxoid and CCL3 improve dendritic cell vaccines in mice and glioblastoma patients. Nature. 2015;519(7543):366-9.

131. Carmi Y, Spitzer MH, Linde IL, Burt BM, Prestwood TR, Perlman N, et al. Allogeneic IgG combined with dendritic cell stimuli induce antitumour Tcell immunity. Nature. 2015;521(7550):99-104.

132. Carreno BM, Magrini V, Becker-Hapak M, Kaabinejadian S, Hundal J, Petti AA, et al. Cancer immunotherapy. A dendritic cell vaccine increases the breadth and diversity of melanoma neoantigen-specific T cells. Science. 2015; 348(6236):803-8

133. Tanyi J, Bobisse S, Ophir E, Tuyaerts S, Roberti A, Genolet R, et al. Personalized cancer vaccine effectively mobilizes antitumor $T$ cell immunity in ovarian cancer. Sci Transl Med. 2018;10:436. 
134. Li C, Liang S, Zhang C, Liu Y, Yang M, Zhang J, et al. Allogenic dendritic cell and tumor cell fused vaccine for targeted imaging and enhanced immunotherapeutic efficacy of gastric cancer. Biomaterials. 2015;54:177-87.

135. Robbins PF, Lu YC, El-Gamil M, Li YF, Gross C, Gartner J, et al. Mining exomic sequencing data to identify mutated antigens recognized by adoptively transferred tumor-reactive T cells. Nat Med. 2013;19(6):747-52.

136. Moynihan KD, Opel CF, Szeto GL, Tzeng A, Zhu EF, Engreitz JM, et al. Eradication of large established tumors in mice by combination immunotherapy that engages innate and adaptive immune responses. Nat Med. 2016;22(12):1402-10.

137. Sockolosky JT, Dougan M, Ingram JR, Ho CC, Kauke MJ, Almo SC, et al. Durable antitumor responses to CD47 blockade require adaptive immune stimulation. Proc Natl Acad Sci U S A. 2016;113(19):E2646-54.

138. Koh E, Lee EJ, Nam GH, Hong Y, Cho E, Yang Y, et al. Exosome-SIRPalpha, a CD47 blockade increases cancer cell phagocytosis. Biomaterials. 2017;121: $121-9$.

139. He $Y$, Bouwstra R, Wiersma VR, de Jong $M$, Jan Lourens $H$, Fehrmann $R$, et al. Cancer cell-expressed SLAMF7 is not required for CD47-mediated phagocytosis. Nat Commun. 2019;10(1):533.

140. Kiss B, van den Berg NS, Ertsey R, McKenna K, Mach KE, Zhang CA, et al. CD47-targeted near-infrared photoimmunotherapy for human bladder cancer. Clin Cancer Res. 2019;25(12):3561-71.

141. Zhang $X$, Fan J, Wang S, Li Y, Wang Y, Li S, et al. Targeting CD47 and autophagy elicited enhanced antitumor effects in non-small cell lung cancer. Cancer Immunol Res. 2017;5(5):363-75.

142. O'Donnell JS, Long GV, Scolyer RA, Teng MW, Smyth MJ. Resistance to PD1/ PDL1 checkpoint inhibition. Cancer Treat Rev. 2017;52:71-81.

143. Marin-Acevedo JA, Soyano AE, Dholaria B, Knutson KL, Lou Y. Cancer immunotherapy beyond immune checkpoint inhibitors. J Hematol Oncol. 2018;11(1):8.

144. Mezzadra R, Sun C, Jae L, Gomez-Eerland R, de Vries E, Wu W, et al. Identification of CMTM6 and CMTM4 as PD-L1 protein regulators. Nature. 2017:549(7670):106-10.

145. Yang X, Zhang X, Fu ML, Weichselbaum RR, Gajewski TF, Guo Y, et al. Targeting the tumor microenvironment with interferon-beta bridges innate and adaptive immune responses. Cancer cell. 2014;25(1):37-48.

146. Overacre-Delgoffe AE, Chikina M, Dadey RE, Yano H, Brunazzi EA, Shayan G, et al. Interferon-gamma crives Treg fragility to promote anti-tumor immunity. Cell. 2017;169(6):1130-1141.e1111.

147. Pasare C, Medzhitov R. Toll pathway-dependent blockade of CD4+CD25+ T cell-mediated suppression by dendritic cells. Science. 2003;299(5609):1033-6.

148. Yang K, Blanco D, Neale G, Vogel P, Avila J, Clish C, et al. Homeostatic control of metabolic and functional fitness of T cells by LKB1 signalling. Nature. 2017;548(7669):602-6.

149. Lu Y, Zhang M, Wang S, Hong B, Wang Z, Li H, et al. p38 MAPK-inhibited dendritic cells induce superior antitumour immune responses and overcome regulatory T-cell-mediated immunosuppression. Nat Commun. 2014:5:4229

150. Merad M, Salmon H. Cancer: a dendritic-cell brake on antitumour immunity. Nature. 2015:523(7560):294-5.

151. Cubillos-Ruiz JR, Silberman PC, Rutkowski MR, Chopra S, Perales-Puchalt A, Song $\mathrm{M}$, et al. ER stress sensor XBP1 controls anti-tumor immunity by disrupting dendritic cell homeostasis. Cell. 2015;161(7):1527-38.

152. Ogasawara M, Miyashita M, Yamagishi Y, Ota S. Phase I/II pilot study of Wilms' tumor 1 peptide-pulsed dendritic cell vaccination combined with conventional chemotherapy in patients with head and neck cancer. Ther Apher Dial. 2019;23(3):279-88.

\section{Publisher's Note}

Springer Nature remains neutral with regard to jurisdictional claims in published maps and institutional affiliations.

Ready to submit your research? Choose BMC and benefit from:

- fast, convenient online submission

- thorough peer review by experienced researchers in your field

- rapid publication on acceptance

- support for research data, including large and complex data types

- gold Open Access which fosters wider collaboration and increased citations

- maximum visibility for your research: over $100 \mathrm{M}$ website views per year

At $\mathrm{BMC}$, research is always in progress.

Learn more biomedcentral.com/submissions 